\title{
AS REFORMAS TRABALHISTAS NO MUNDO: A FLEXIBILIZAÇÃO NO TEMPO DE TRABALHO E NA REMUNERAÇÃO COMO VETOR DE PRECARIZAÇÃO
}

\section{Working reforms in the world: flexibilization in working time and remuneration as a precarization vector}

Vinícius Ferreira Lins (UFBA)

Adalberto Oliveira da Silva (UFBA)

Informações do artigo

Recebido em 31/07/2019

Aceito em 10/09/2019

doi>: https://doi.org/10.25247/2447-861X.2019.n248.p481-513

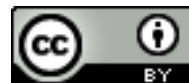

Esta obra está licenciada com uma Licença Creative Commons Atribuição 4.0 Internacional.

\section{Como ser citado (modelo ABNT)}

LIRA, Vinícius Ferreira Lins; SILVA, Adalberto Oliveira da. As reformas trabalhistas no mundo: a flexibilização no tempo de trabalho e na remuneração como vetor de precarização. Cadernos do

CEAS: Revista Crítica de Humanidades. Salvador, $\mathrm{n}$. 248, set./dez., p. 481-513, 2019. DOI: https://doi.org/10.25247/2447-861X.2019.n248.p481-513

\begin{abstract}
Resumo
O objetivo deste artigo é a discussão sobre os impactos no tempo de trabalho e na remuneração diante das experiências de reformas trabal histas, pois entendemos que surgem evidências de aumento da precarização do trabalho. Constata-se um processo de polarização, em razão da possibilidade de uma situação de tendência de limite zero para a util ização da força de trabalho e, consequentemente, da remuneração recebida diante das relações de trabal ho flexíveis. Para a caracterização deste processo, centramos a nossa atenção em dois aspectos: o primeiro, condiz com os impactos nas relações de trabalho decorrentes dos diferentes tipos de contrato de trabal ho, onde a flexibilização do tempo de trabalho e da remuneração se tornam evidentes; o segundo, refere-se ao processo de polarização em si, que possibilita a inexistência de jornadas e salários garantidos, por parte dos trabal hadores, representando uma condição de subsunção real do trabal ho ao capital. Diante de dados empíricos de países selecionados, no período de 2000 a 2017, apresentamos evidências de subutilização da força de trabalho e de precariedade salarial, constituindo vetores de precarização decorrentes do processo de flexibilização dos mercados de trabal ho.
\end{abstract}

Palavras-chave: Reforma Trabalhista. Tempo de trabalho. Remuneração. Precarização. Polarização.

\section{Abstract \\ The objective of this article is the discussion about the impacts on working time and remuneration in the face of labor reform experiences, because we believe that there is evidence of increased precariousness of work. There is a polarization process, due to the possibility of a situation of zero limit tendency for the use of the workforce and, consequently, the remuneration received in the face of flexible working relationships. For the characterization of this process, we focus our attention on two aspects: the first, is consistent with the impacts on labor relations resulting from different types of employment contract, where the flexibility of working time and remuneration become evident; The second refers to the process of polarization itself, which makes it impossible for workers to have no hours and guaranteed wages, representing a condition of real subsumption of labor to capital. Given empirical data from selected countries, from 2000 to 2017, we present evidence of underutilization of the workforce and wage precariousness, constituting precariousness vectors arising from the process of flexibilization of labor markets.}

Keywords: Labor reform. Working time. Remuneration. Precariousness. Polarization. 


\section{Introdução}

A desregulamentação das leis trabalhistas, no sentido de flexibilização da proteção ao emprego, tornou-se um imperativo na etapa do capital ismo flexível. Dois argumentos norteiam esse discurso: o primeiro, defende a necessidade de reformas porque as legislações trabalhistas estão defasadas perante o surgimento de "novas relações de trabalho"; e o segundo, em razão do custo do trabalho, ao caracterizá-lo como principal fator para os ganhos de competitividade no mercado internacional ${ }^{1}$.

Em tese, as reformas trabalhistas consistem de medidas ou procedimentos jurídicos cuja finalidade é conferir às empresas a possibilidade de ajustar a sua produção, o emprego e as condições de trabalho diante das contingências rápidas e/ou contínuas do sistema econômico. Assim, em atendimento a essa demanda, as experiências de reformas trabal histas introduzem uma profusão de formas flexíveis², que, além do contrato-padrão por tempo indeterminado, passam a oferecer uma ampla variedade de formas flexíveis e precárias: estágio, jovem aprendiz, contratação temporária, terceirização, home-office, trabalho intermitente, autônomo e em regime de tempo parcial.

Destacamos que esta variedade de formas de contratações aprofunda o processo de dualização dos mercados de trabalho, sendo que, no caso do trabalho intermitente, verifica-se uma tendência de polarização mais contundente entre os trabalhadores. Em termos práticos, no tocante ao tempo de trabalho e à remuneração, possibilita uma tendência a limite zero, ou seja, o tempo de trabalho pode oscilar entre uma extensão sem limites até uma total inatividade e, no caso da remuneração, entre condiçõessem limites para o recebimento por tarefas (ou peça mínima) até casos sem garantia de remuneração.

Essas modalidades de contratação não são completamente novas. No caso do contrato intermitente, tem origem em meados da década de 1980, como formas jurídicas da flexibilização extrema do trabalho nas legislações de países como a Inglaterra, com o "contrato zero hora"; Espanha, como "trabajo fijo discontínuo"; e Portugal, como "trabal ho alternado/trabalhoa chamada. Convém, portanto, escrutinar as características desta polarização colocada em curso e contribuir para o entendimento deste movimento de precarização do trabalho, sobre os vetores do tempo de trabalho e da remuneração, no alvorecer do séculoXXI3.

\footnotetext{
${ }^{1}$ Salientamos que essas alterações estão inseridas em um contexto mais amplo, identificado com as sucessivas reformas trabalhistas que buscam a "flexibilização" da regulação do trabalho no que tange ao uso, à remuneração e à demissão da força de trabalho (RIGOLETTO \& PÁEZ, 2018, p.186).

2 Para maiores detalhes sobre as metamorfoses do mundo do trabalho e as formas laborais flexíveis e precárias, ver ANTUNES E ALVES (2004).

3 O trabalho precarizado está associado não só ao tipo de contrato, como, também, a um conjunto de outras variáveis que se enquadram na história econômica e social de cada país, a saber, a segurança social, os direitos
} 
O tempo de trabalho, isto é, a extensão e a intensidade da jornada de trabalho, esteve desde sempre no cerne da disputa capital/trabalho. Nas sociedades pré-industriais, o tempo de trabalho estava vinculado à duração da luz solar, perfazendo uma jornada de 10 a 14 horas diárias, sete dias por semana. Com o advento da eletricidade e da Revolução Industrial, o tempo de trabalho pôde ser modificado. A transição da sociedade agrária para a industrial trouxe consigo o aumento das horas de trabalho. As jornadas aumentaram e há registros de práticas de até 18 horas diárias ou mesmo de labor até o limite da exaustão humana (ENGELS, 2010). Com a organização dos trabalhadores e o surgimento dos sindicatos, engendrou-se uma disputa pela diminuição e padronização do tempo de trabalho. A regulamentação da jornada padrão de $8 \mathrm{~h} / \mathrm{dia}$ - 48h/semana, bem como feriados como dias de não-trabalho (entre outras medidas que tornaram o trabalho mais humano), foi instituída primeiro na Rússia, logo após a Revolução de 1917. A Liga das Nações, em 1919 (Convenção no.1 da OIT), sancionou esta como a jornada padrão (embora apenas restrita a empreendimentos industriais). Em 1938, nos Estados Unidos, implementa-se a jornada padrão de 40 horas semanas distribuídas em 5 dias da semana, pelo Fair Labour Standard Act (FLSA), seguindo a convenção no 47 da OIT, de 1935 (DAL ROSSO, 2017; MESSENGER, 2018).

Assim, as jornadas de tempo integral ocuparam o lugar de jornada-padrão não por um processo "natural" do capitalismo, mas como fruto de muita luta e resistência dos trabalhadores, configurando um contra movimento que impunha limites à tendência inerente de subsunção do trabalho pelo capital via mecanismo de mercado (POLANYI, 2012). A hipótese que se pretende jogar luz aqui é que a transição da sociedade industrial para a sociedade de serviços/digital promove uma nova investida sobre os tempos de não trabalho, constituindo-se, assim, em um ponto de inflexão. Isto não significa dizer que há uma reversão literal às condições do período da Revolução Industrial. 0 processo é mais complexo.

A flexibilidade no mercado de trabalho ora aparece como uma condição estrutural sine qua non para assegurar o crescimento econômico (via diminuição do desemprego e aumento da produtividade), como advogado no icônico Jobs Study da OECD, de 1994 (DOSI et al, 2016):

\footnotetext{
Muitos padrões tradicionais na organização do trabalho e do tempo de trabalho permanecem consagrados na legislação ou nos acordos coletivos. Desta forma, impedem a flexibilidade do mercado de trabalho e, indiretamente, a criação de emprego. Arranjos menos rígidos para o horário de trabalho diário, semanal, anual e de tempo de vida poderiam atender aos requisitos corporativos e às aspirações dos trabalhadores (...) arranjos mais flexíveis de horário de trabalho também facilitariam uma maior participação ao longo da vida das mulheres (OECD, 1994, p.32)
}

sociais, a legislação laboral, o nível salarial, a oferta do mercado de trabalho, entre outras. Para maiores detalhes deste debate, ver SÁ (2010). 
Consequentemente, o terceiro item do seu decálogo de recomendações versa precisamente sobre "aumentar a flexibilidade do tempo de trabalho":

Arranjos mais flexíveis de tempo de trabalho poderiam resultar de medidas que: removessem obstáculos na legislação trabalhista que impedem o surgimento de acordos flexíveis de horário de trabalho e incentivassem as negociações entre empregador e empregado sobre o horário de trabalho flexível e trabalho em meioperíodo; estendessem o trabalho a tempo parcial no setor público. (OECD, 1994, p.48)

Ora aparecem também como respostas ótimas aos momentos de crise, como defendido pela Comissão Europeia em 2010 (EUROPEAN COMISSION, 2010 apud CLAUWAERT e SCHÖMANN, 2012, p.6):

as políticas flexicurity são o melhor instrumento para modernizar os mercados de trabalho: devem ser revisitadas e adaptadas ao contexto pós-crise, a fim de acelerar o ritmo das reformas, reduzir a segmentação do mercado de trabalho, apoiar a igualdade entre os gêneros e fazer as transições compensarem.

Ou seja, a flexibilização proposta pelas reformas trabalhistas, em particular a do horário de trabalho, se coloca, ao fim e ao cabo, como uma panaceia, resolvendo gargalos estruturais e crises conjunturais, bem como servindo de atenuante para as distorções de gênero incrustadas no mercado de trabalho.

Argumenta-se que alterações no tocante ao tempo de trabalho buscam desempenhar uma dupla função: 1.) tempos de não trabalho são transformados em tempos laborais, ao mesmo tempo em que o limite entre um e outro torna-se cada vez mais turvo 2.) tempos de trabalho não são reconhecidos como tal, levando ao descomprometimento da empresa tanto do ponto de vista de remuneração quanto de responsabilidadescom saúde e segurança do trabalho.

O que se mostra adiante é que há basicamente duas formas de promover mudanças no tempo de trabalho. A primeira delas é interferindo diretamente na lei e nas regulações que versam sobre duração e distribuição das horas de trabalho ou nos limites atinentes às formas de contratação caracterizadas pela atipicidade quanto ao tempo de trabal ho, e.g. contratos intermitentes e de tempo parcial. Outra forma, indireta, é a legitimação de acordos a nível de empresa ou indústria, que permitem arranjos de tempo de trabalho à margem de regulação mais ampla (opt out). Esses acordos, em geral, preveem termos menos vantajosos não apenas em relação à magnitude e organização do tempo de trabalho, mas também na organização de licenças, remuneração, recrutamento e conciliação entre vida profissional e pessoal (CLAUWAERT, SCHÖMANN e BÜTTGEN, 2016c).

A flexibilização, ao se estender também para a questão da remuneração do trabalho, o conceito de corrosão da condição salarial, desenvolvido por Castels (1998), sintetiza um processo de 
substituição de um conjunto de empregos, caracterizados por salários superiores ao salário mínimo, benefícios sociais e segurança no emprego, por outros com salários mais baixos, menos benefícios e sem segurança no emprego.

No caso da reforma trabal hista, a remuneração é atacada negativamente de forma direta, ao definir como indenizatórias parcelas nitidamente salariais e permitindo a redução de salários sem uma diminuição proporcional do tempo trabal hado, ou de forma indireta, por liberar os processos de terceirização para qualquer atividade e ampliar o uso de contratos de trabalho atípicos (temporários, tempo parcial e intermitente) e formas de emprego disfarçadas, como é o caso dos trabalhadores autônomos, entre outras situações extremamente prejudiciais aos trabalhadores e à própria dinamização da economia.

Os contratos típicos sofrem uma descaracterização dos componentes da remuneração, através de cortes das parcelas salariais - como adicionais (horas extras, trabalho noturno, periculosidade e insalubridade), comissões, gratificações, abonos, diárias, entre outros - ou, simplesmente, por sua redução direta. Ao mesmo tempo, estimula-se o desenvolvimento de remuneração variáveis e indiretas por meio de Programas de Participação nos Lucros e Resultadose o pagamento por meio de benefícios (serviços de alimentação, saúde, transporte, etc.), todos sem caráter salarial4.

Nos contratos atípicos, o movimento é ainda mais contundente. O impacto na remuneração advém de mudanças contundentes na morfologia social do trabal ho, através da diminuição no tempo de trabalho, que é a base de mensuração da remuneração, vigente nos contratos de tempo parcial, chegando a modalidades cujo intuito é eliminar qualquer limite mínimo remuneratório, onde os salários podem chegar a zero, possibilitados pelos contratos intermitentes e/ou autônomos.

De forma mais geral, esse processo representa uma subsunção da vida do trabalhador - em toda sua extensão - ao arbítrio do capital, estando o trabal hador na condição de escravo do tempo do capital e, consequentemente, ficando à disposição de sua lógica de valorização. Como afirma Antunes e Alves (2004, p.343-344):

À primeira vista, poderia parecer mais oportuno denominá-lo "submissão", já que se trata de expressar a relação que surge quando o trabalhador vende sua força de trabalho ao capital, a ele se submetendo. No entanto, subsunção expressa que a força de trabalho vem a ser, ela mesma, incluída e como que transformada em capital: o trabalho constitui o capital. Constitui-o negativamente, pois é nele

\footnotetext{
${ }_{4}^{4}$ A parte variável da remuneração e os salários indiretos não são considerados salários e, portanto, sobre os seus valores não há incidência nos encargos sociais - o que compromete as fontes de financiamento do fundo público - e nos direitos trabalhistas vinculados ao assalariamento, tais como férias, aposentadoria, $13^{\circ}$ salário etc. - o que traz prejuízos ao conjunto dos trabalhadores e a estruturação do mercado de trabalho.
} 
integrado no ato de venda da força de trabalho, pelo qual o capital adquire, com essa força, o uso dela; uso que constitui o próprio processo capitalista de produção.

Diante deste processo complexo e de múltiplas determinações, nosso caminho analítico, ao centrar-se nos impactos sobre o tempo de trabal ho e na remuneração, busca elementos que apontem as tendências precarizantes inerentes à ampliação do universo de relações de trabalho. Como iremos salientar, as reformas trabalhistas, ao ampliarem o leque de formas de contratação, produzem as condições de subutilização da força de trabalho e a ocorrência de uma precariedade salarial, subjacente aos contratos atípicos, e que enfraquece a condição dos trabal hadores permanentes.

Nosso objetivo consiste, especificamente, em examinar como os novos tipos de contratos de trabalho modificam a dinâmica do tempo de trabalho e da remuneração dos trabalhadores, através do papel exercido pelos contratos de tempo parcial e trabalho intermitente, nos respectivos países selecionados ao longo dos anos 2000. Entendemos que essas duas formas de contratação exacerbam a lógica do trabalho flexível, em atendimento às exigências dos mercados e contribuindo para uma maior exploração do trabal ho pelo capital ${ }^{5}$.

Além desta introdução e das considerações finais, o artigo divide-se em três seções. A primeira fala do tempo de trabalho e da remuneração em termos gerais, dando um prelúdio sobre o debate em torno deste eixo e fazendo uma comparação entre grandes regiões do mundo. A segunda seção versa sobre mudanças recentes ocorridas em países selecionados, com foco nos respectivos eixos, efetivadas por suas respectivas reformas trabal histas. Por fim, a terceira seção apresenta dados empíricos dos países selecionados - Alemanha, Espanha, França, Portugal e Reino Unido -, que mostram o movimento de subutilização da força de trabalho e rebaixamento dos salários, dando subsídios à caracterização das reformas como um processo de maior precarização no mundo do trabalho.

\section{Um breve olhar panorâmico}

Hoje enfrentamos um processo que busca "implodir" a base-padrão da regulação salarial propriamente dita, realizando mutações na forma-salário, na jornada de trabalho e no local de trabalho. Neste processo chama a atenção a reformulação dos parâmetros laborais, onde a precariedade salarial e as longas e intermitentes jornadas de trabal ho são os eixos onde o tempo de vida do trabalhadoré reduzido ao tempo de trabalho.

5 Além disso, aprofunda o processo de precarização subjacente às novas relações de trabalho, quando partimos do conceito de trabalho precário como sinônimo de emprego que envolve insegurança contratual, ou seja, a segurança de emprego enfraquecida para os trabalhadores permanentes e subjacente às formas contratuais atípicas. 
Como aludido anteriormente, a jornada de trabal ho padrão, a partir de um processo de luta e conquista dos trabalhadores estabelece-se como 40 horas semanais. No entanto, como se observa na figura 1, as horas semanais normais estatuárias diferem entre os países. Há casos em que, por lei, situam-se abaixo da "jornada padrão", como França, Austrália e Dinamarca. Por outro lado, há outros onde se admite legalmente mais horas do que o recomendado pela OIT (inclusive acima de 48h), notadamente países da periferia do sistema. Anxo e Kalrsson (2019) assinalam que, no Reino Unido, por exemplo, o nível descentralizado de regulação do horário de trabal ho e a possibilidade de optar pela exclusão (opt-out) de diretivas da União Europeia implicam que não existe uma regra ou norma geral em relação às horas extraordinárias.

Figura 1 - Horas semanais normais estatutárias em todo o mundo (2017)

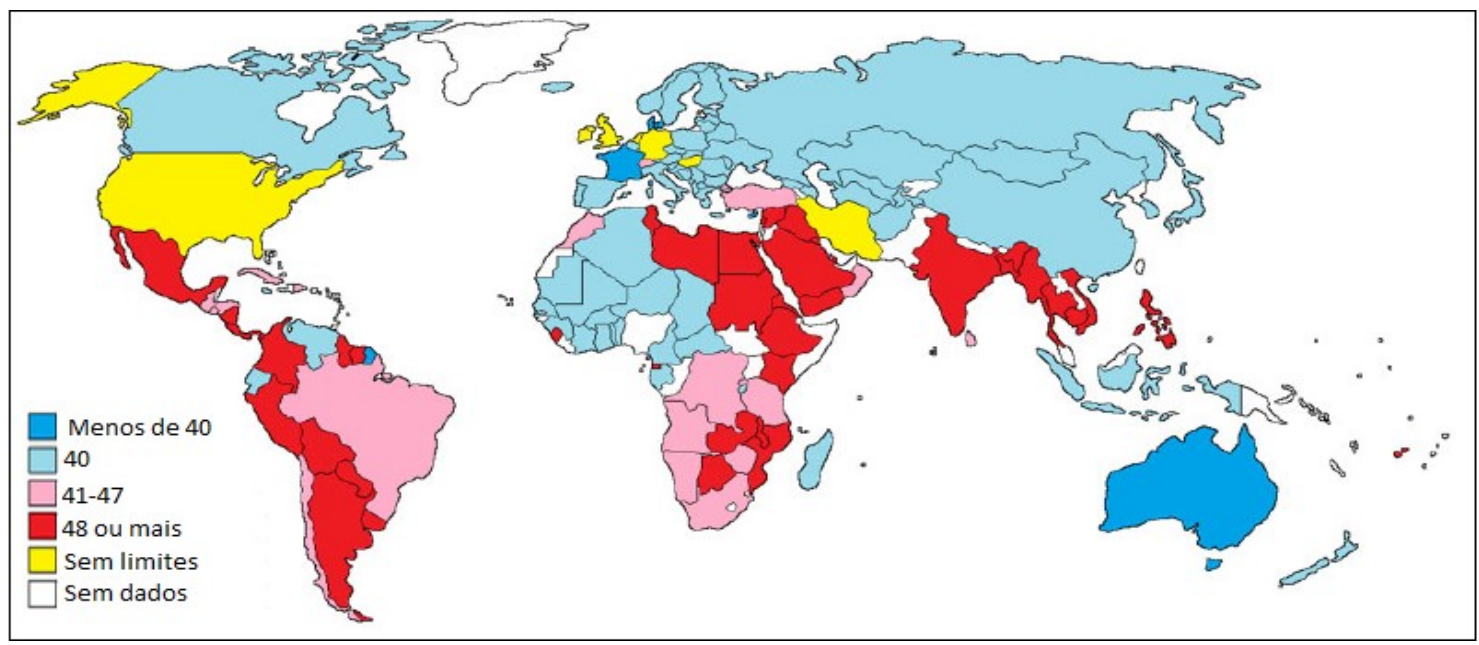

Fonte: ILO (2018).

A inexistência da adoção de uma regra universal sobre a jornada padrão acaba por engendrar dificuldades em relação à comparação da incidência de horas extras nos países com diferentes estruturas regulatórias e, por conseguinte, no estudo das consequências individuais das horas extras em uma perspectiva internacional (ANXO e KARLSSON, 2019). Isso é especialmente importante porque, de acordo com Messenger (2018), está em curso um fenômeno de bifurcação do tempo de trabalho. Essa bifurcação se caracteriza pelo fato de que, cada vez mais, a força de trabalho vem sendo dividida entre segmentos que, de um lado, passam horas excessivas e, de outro, horas curtas / variáveis. Ambos os segmentos marcam diferenças substanciais no que se refere à questão de gênero quanto ao nível de desenvolvimento. 
Gráfico 1 - Horas excessivas de trabalho (mais de 48 horas por semana): estimativas globais e regionais, empregototal, último ano disponível (porcentagens)

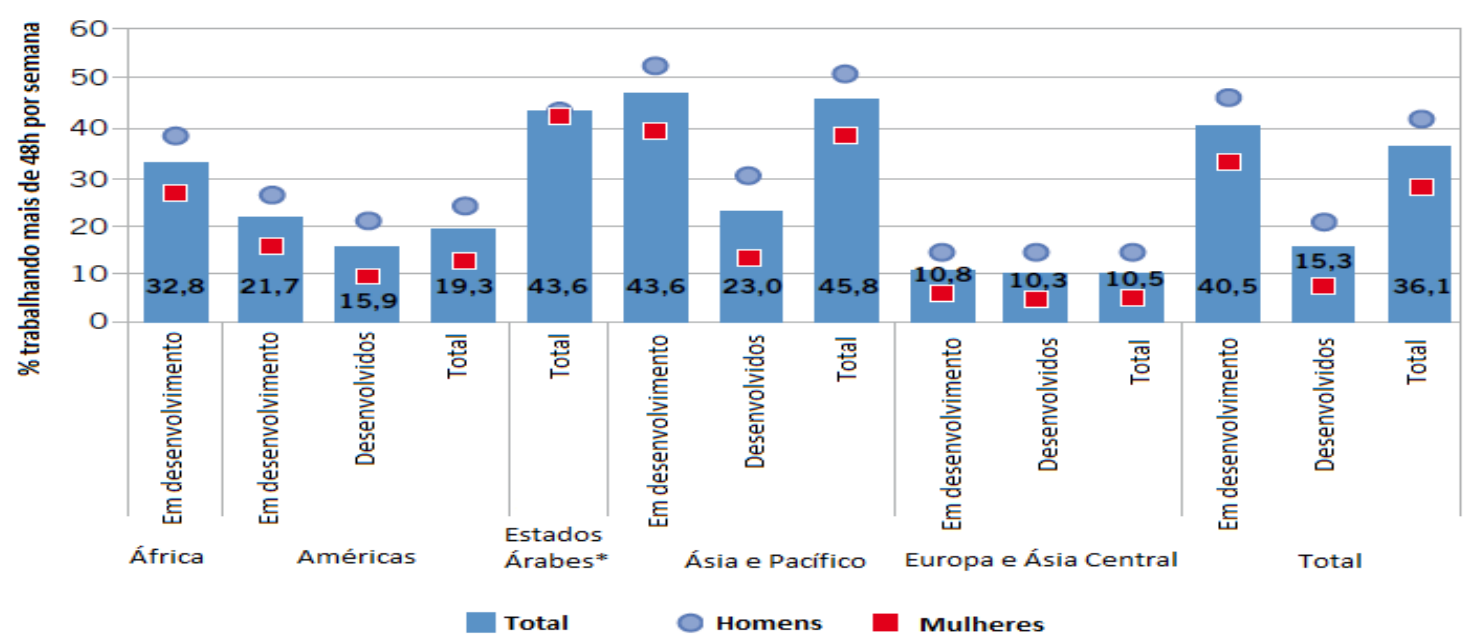

Nota: Estimativas globais baseadas em 131 países representando 95 por cento do emprego mundial. Dados para o último ano disponível: 2013 ou posterior (principalmente 2014-15) para 80 dos países abrangidos.

* Estados Árabes: o número de países considerados é insuficiente para tirar conclusões sobre essas estimativas regionais.

Fonte: Messenger (2018)

O gráfico 1 mostra o percentual do emprego total que trabalha horas excessivas (considerando a jornada padrão de 40h). Em linhas gerais, percebe-se que mais de um terço $(36,1 \%)$ da força de trabal ho mundial labora mais de 48 horas por semana. Nota-se, também, que se trata de um fenômeno mais difundido entre os países em desenvolvimento do que nos países desenvolvidos. Cabe destacar que, por fatores culturais, a região da Ásia e do Pacífico apresentam índices relativamente altos mesmo para os países desenvolvidos (23,0\%).

Ademais, para todas as regiões, os dados mostram uma incidência maior de horas excessivas de trabalho para os homens. No entanto, eles encobrem uma realidade importante em relação à divisão do trabalho relativa ao gênero. Trata-se da realização de trabalho de reprodução social (não pago e não contabilizado) que geralmente fica a cargo das mulheres. Por exemplo, para que seja possível os maridos realizarem essas horas extras/excessivas, certamente as esposas, como tradicionalmente está enraizado (em que pese a progressiva incorporação das mulheres no mercado de trabalho [paid work]), tomam conta das crianças e/ou realizam os necessários e fundamentais trabalhos domésticos.

Outro traço importante que Messenger (2018) ressalta que pode estar relacionado com o excesso de trabal ho é que mais horas de trabal ho, bem como trabal ho em tempos habitualmente de não-trabalho, parecem estar correlacionados com teletrabal ho e/ou atividade s relacionadas às novas tecnologias de informação e comunicação (T/ICTM). "As horas de trabalho (,...) em particular, dos trabalhadores T/ICTM de mobilidade elevada são normalmente superiores às horas dos trabal hadores que trabalham sempre nas instalações do empregador" (MESSENGER, 2018, p.21). Ou seja, ainda 
que possam gozar de um maior grau de "autonomia" relativa no que toca ao tempo de trabalho, tal benefício vem à custa de mais horas e da indefinição dos limites da vida profissional e privada.

O gráfico 2, por sua vez, traz os percentuais da força de trabalho que laboram poucas horas de trabalho, isto é, menos de 35 horas por semana. Trata-se de uma característica de formas atípicas de empregos (por definição, por exemplo, do contrato a tempo parcial) que oferecem remuneração relativamente baixa e uma menor cobertura de benefícios (quando existente), e, muitas vezes, têm arranjos de horários mais variáveis e/ou imprevisíveis. Em suma, envolve trabalho pouco qualificado e concede aos trabalhadores autonomia limitada. Além disso, amiúde encobre o chamado "subemprego relacionado ao tempo", ou seja, pessoas que estão dispostas e disponíveis para aumentar seu tempo de trabalho.

Gráfico 2 - Poucas horas de trabalho (menos de 35 horas por semana): estimativas globais e regionais, empregototal, último ano disponível (percentagens)

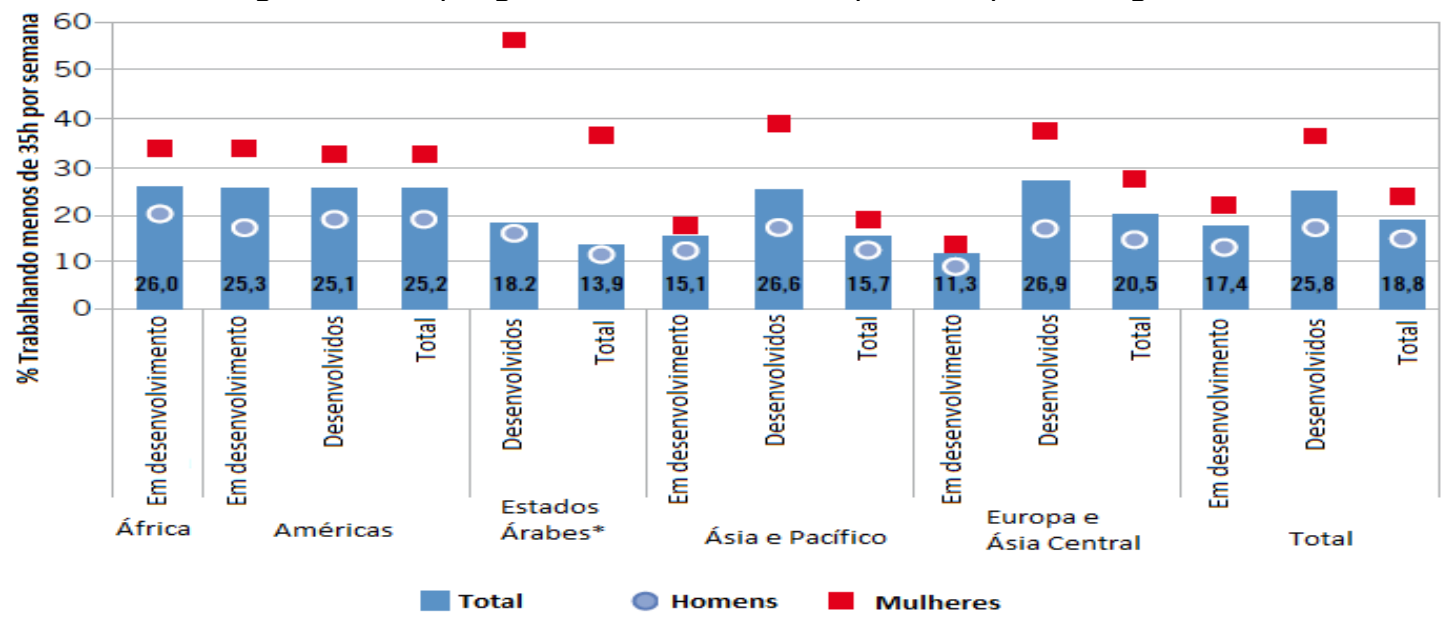

Nota: Estimativas globais baseadas em 131 países representando 95 por cento do emprego mundial. Dados para o último ano disponível: 2013 ou posterior (principalmente 2014-15) para 80 dos países abrangidos.

* Estados Árabes: o número de países considerados é insuficiente para tirar conclusões sobre essas estimativas regionais. Fonte: Messenger (2018)

Ao contrário da jornada excessiva discutida anteriormente, o trabalho de horas muito curtas, de uma maneira geral, é relativamente mais predominante nos países desenvolvidos ( $25,8 \%$ contra $17,4 \%$ nos países em desenvolvimento). Isso pode estar relacionado à utilização de arranjos de trabalho de curta duração como uma medida de superação da crise global de 2008, muito utilizada em países desenvolvidos (adiante discute-se isso). Nota-se, também, o predomínio das mulheres, cuja diferença em relação aos homens é ainda maior, relativamente, nos países desenvolvidos. Messenger (2018) assinala, ainda, que a proporção de trabalhadores que têm horário de trabalho muito curto é maior entre os trabalhadores em emprego informal do que os trabalhadores em emprego formal em todas as regiões do mundo. 
No caso da remuneração do trabalho, a heterogeneidade dos níveis salariais entre os países desenvolvidos e em desenvolvimento é de conhecimento de todos, mas as consequências para a trajetória de crescimento e comportamento das remunerações advindas da clivagem dos trabalhadores, em torno do tempo de trabalho, parecem ser compartilhadas indistintamente pelos diferentes países e regiões do mundo. Este cenário ficou mais evidente com o processo de desregulamentação trabalhista, que, no afã de superar as recorrentes crises, acabou por promover reduções salariais com repercussões negativas tanto no mercado de trabal ho, quanto no crescimento da produtividade.

Como apontam Vergeer e Kleinknecht (2014), tais transformações vão na contramão dos resultados esperados, já que detectam que mudanças nas taxas de crescimento dos salários levama mudanças no crescimento da produtividade do trabal ho. Logo, grande parte do debate em torno da produtividade não pode ser explicada apenas pela contratação de mão de obra pouco produtiva, em razão da flexibilização dos mercados de trabal ho propiciar condições para o crescimento do trabalho intensivo, que, mesmo diante de crescimento do emprego, resulta em baixas taxas de produtividade.

Soma-se ao diagnóstico dos autores, o fato de que o crescimento dos salários reais se apresenta mais modesto em países com legislação trabalhista flexível do que os de legislação mais rígida, sendo um dos fatores para esse menor crescimento do salário sua relação com uma elevação substancial das horas de trabalho. Isso compromete muito a retórica pró-reformas, pois os autores ressaltam que um menor crescimento salarial não resultou num maior crescimento do PIB nos países mais flexíveis em comparação aos países mais rígidos, ao detectarem que não há evidências de uma relação clara entre o crescimento do PIB e os salários reais, mas sim, entre crescimento dos salários e aumento da produtividade do trabalho (VERGEER E KLEINKNECHT, 2014).

Portanto, o debate em torno da força de trabalho como simples custo de produção acaba por eclipsar o seu real papel na dinâmica econômica, logo, ao ser encarado desta forma, compreende uma das explicações sobre a necessidade de reformas recorrentes nas legislações trabalhistas, em razão de não conseguir respostas satisfatórias diante das taxas de crescimento erráticas apresentadas pelas economias no cenário mundial. Isso é resultado de uma negligência sobre o papel da remuneração do trabalho como fator importante para a demanda agregada e o crescimento do produto.

Diante dos aspectos apontados, quanto ao tempo de trabalho e à remuneração, os principais fatores que podem ser elencados são: (i) há um processo de bifurcação em torno do tempo de trabalho, entre trabalhadores com horas excessivas de trabalho, enquanto outros apresentam jornadas curtas e variáveis; (ii) as maiores jornadas de trabalho são mais recorrentes nos países em desenvolvimento em relação aos países desenvolvidos; (iii) o desenvolvimento de técnicas de teletrabalho, sobre diferentes formas de contrato de trabalho, elevam a quantidade de horas trabalhadas; (iv) os salários declinam a níveis inferiores aos apresentados no período fordista, pois a 
tendência de crescimento dos salários será canalizada para a elevação dos lucros; e, por fim, (v) as remunerações nos contratos atípicos resultam em diminuição dos salários percebidos pelos trabalhadores e cresce o número de trabalhadores involuntários sobre contratos de trabalho parcial ou intermitente.

\section{Alterações recentes no tempo de trabalho e na remuneração de países selecionados}

A questão do tempo de trabalho é particularmente importante devido ao seu tratamento como um mecanismo de ajustamento essencial aplicado nas reformas do mercado de trabal ho em diversos países (LANG, CLAUWAERT e SCHÖMANN, 2013). Messenger (2018) identifica quatro elementos a partir dos quais o tempo de trabalho pode ser flexibilizado: (i) o número de horas trabalhadas em cada dia de trabalho; (ii) o número de horas trabalhadas por semana; (iii) as horas específicas (tempo) de trabalho durante um dia de trabalho; e (iv) os dias específicos da semana durante os quais o trabalho é realizado. Este conjunto de elementos compõe a forma "direta" de modificação no tempo de trabalho.

Uma outra via de atuação é a indireta, pelo fomento das negociações em detrimento de disposições estatutárias/legislativas e, concomitantemente, como lados de uma mesma moeda, o enfraquecimento do poder de barganha dos representantes dos trabalhadores. Trata-se da determinação cada vez mais específica do poder de influenciar a duração e a distribuição do tempo de trabalho. Anxo e Karlsson (2019) distinguem quatro níveis de regulamentação. Embora possa haver uma conjugação de vários destes níveis, um deles tende a predominar: (i) a nível nacional (lei estatutária ou acordos interprofissionais) (ii) ao nível da indústria via acordos coletivos (acordos setoriais) (iii) ao nível da empresa através de negociações descentralizadas (acordos coletivos de empresas) (iv) no nível individual por meio de acordos entre empregador e empregado.

A intenção é abrir a possibilidade a posteriores alterações desfavoráveis aos trabalhadores quanto a diversos elementos que estejam relacionados direta ou indiretamente ao tempo de trabalho. Por exemplo, flexibilização de regras relativas aos contratos atípicos, alargando a sua duração máxima e/ou aumentando o número máximo de renovações; ampliação das opções de overtime (horas extraordinárias), bem como mudança nas suas regras de compensação; alterações nos tempos de descanso, permissão para os empregadores reduzirem o tempo de trabalho com redução de remuneração (às vezes com ajuda de subsídios governamentais) e, enfim, permissão aos empregadores para acomodar a alocação de horas de acordo com suas necessidades (CLAUWAERT e SCHÖMANN, 2012; LANG, CLAUWAERT e SCHÖMANN, 2013).

Não sem razão, Anxo e Karlsson (2019) identificam que tem havido, nas últimas décadas, uma tendência geral para uma descentralização da regulação do tempo de trabalho e das horas 
extraordinárias ao nível da indústria e das empresas, bem como uma tendência para uma maior autonomia dos parceiros sociais se afastarem da norma estatutária. Ou seja, a tendência é permitir que os resultados de negociações setoriais, no nível das empresas, e mesmo individuais, se desviem desfavoravelmente (na ótica do trabalhador) da proteção prevista pelos acordos coletivos em instâncias imediatamente maiores ou, até mesmo, pela legislação estatutária. Em que pese avanços em relação ao "direito de se desconectar" (França e, logo em seguida, Espanha), o tom geral das mudanças descritas a seguir é que a legislação trabalhista deve oferecer desembaraço para derrogações de acordos de horário de trabal ho sob o argumento de que se deve proteger o emprego em geral e não os "privilégios" de determinadas ocupações (job protection versus employment protection).

\section{O caso brasileiro}

No Brasil, foram adotados diversos dispositivos que estimulam o aumento da duração do trabalho além do limite semanal de 44 horas. A reforma autoriza, por simples acordo individual, o acréscimo de até duas horas extras najornada de trabalho (art. 59), a extensão da jornada máxima de 10 horas para até 12 horas diárias - com descanso de 36 horas seguintes (art. 59-A) - e o regime de compensação de horas - dispensando pagamento de horas extras - além das 44 horas semanais. Isso ocorre através da regulação do banco de horas, da eliminação das horas in itinere enquanto componentes da jornada de trabalho, e da possibilidade de prolongamento da jornada de trabalho emlocal insalubre.

A reforma também autoriza que o banco de horas seja pactuado por acordo individual, com compensação das horas em até seis meses. Os intervalos para descanso em jornadas de $12 \times 36$ não são mais obrigatórios, podendo ser indenizados. Além disso, se o empregador deixa de conceder, total ou parcialmente, o intervalo intrajornada, o pagamento terá natureza meramente indenizatória, não mais repercutindo para outras parcelas salariais, e será restrito apenas ao período suprimido. Por fim, a negociação coletiva pode reduzir o descanso intrajornada para o limite mínimo de meia hora.

A reforma não retirou diretamente os direitos previstos no artigo $7^{\circ}$ da Constituição Federal, dedicado à regulação do salário mínimo, mas o fez indiretamente, ao criar instrumentos que esvaziam o conteúdo do direito e inviabilizam seu acesso pelos trabalhadores. Ao aumentar a flexibilidade da remuneração, a lei 13.467/2017 retira a natureza salarial de diárias de viagens, ajudas de custo e abonos. A habitualidade deixou de serelemento fundamental para definir o que terá ou não natureza salarial.

Outro aspecto importante, com a mudança da legislação, foi a introdução do contrato de trabalho intermitente, também conhecido como contrato de zero hora, que garante que o 
trabalhador permaneça subordinado ao empregador, sendo que o último pode utilizar o tempo de trabalho do primeiro de acordo com sua necessidade. Trata-se do ápice do controle do tempo de trabalho pelo empregador. $0 \$ 3^{\circ}$ do art. $443 \mathrm{diz}$ :

\30 Considera-se como intermitente o contrato de trabalho no qual a prestação de serviços, com subordinação, não é contínua, ocorrendo com alternância de períodos de prestação de serviços e de inatividade, determinados em horas, dias ou meses, independentemente do tipo de atividade do empregado e do empregador, exceto para os aeronautas, regidos por legislação própria. (BRASIL, 2017)

A redação deixa claro que o trabalho intermitente permite a prestação de serviços de forma descontínua, atendendo às demandas específicas de cada setor, limitando-se o pagamento às horas efetivamente trabalhadas. Ainda, não há nenhuma restrição à aplicação do contrato intermitente, fora os aeronautas por sua especificidade. Assim, o trabal ho intermitente se ajusta perfeitamente a demandas eventuais, como trabalho em fins de semana, atendimento em horários de pico em bares e restaurantes.

Não há, assim, qualquer previsibilidade quanto ao número de horas a serem contratadas, nem à remuneração a ser recebida, causando insegurança para o trabal hador. A remuneração do trabalho intermitente, por ser realizada de acordo com as horas efetivamente trabalhadas, não corresponde ao mínimo estabelecido pelo salário mínimo. O trabalhador fica responsável por gerenciar as horas trabalhadas, sendo que a demanda pelas horas trabalhadas deve ser apresentada com pelo menos três dias de antecedência, e a resposta deve ser dada com um dia de antecedência.

O trabalho intermitente promove a instabilidade e o rebaixamento da remuneração do trabalhador e pode promover a intensificação do trabalho. De acordo com Teixeira et al (2017):

O contrato intermitente se torna um veículo para que trabalhadores que eram CLTistas em tempo integral se tornem "trabalhadores just in time", trabalhando e recebendo estritamente de acordo com as necessidades da empresa. Trata-se de legalizar o estabelecimento de uma nova lógica de subordinação, gestão e controle da força de trabalho, que pode se generalizar por diversos setores da economia. (TEIXEIRA et al, p. 35, 2017)

A vida dos trabalhadores passa a ser completamente vinculada às demandas empresariais de curto prazo, ficando constantemente à disposição dos empregadores.

O fenômeno de bifurcação das horas de trabalho aludido por Messenger (2018) parece estar em curso também no Brasil. O quadro 1 mostra a evolução contínua no número de pessoas desocupadas em faixas de horas abaixo e acima da jornada padrão. Ou seja, nota-se um processo de polarização das jornadas, como ocorrido no Reino Unido, por exemplo(FILGUEIRAS, 2018). 
Quadro 1 - Trabal hadores por conta própria de 14 anos ou mais de idade por Horas efetivamente trabalhadas por semana - Terceiro trimestre do ano-Brasil

\begin{tabular}{|l|l|l|l|l|l|l|}
\hline Faixa de horas/Ano & 2015 & 2016 & 2017 & 2018 & $\sim 15-18$ & $\sim 17-18$ \\
\hline Até 14 & 2.608 .418 & 1.862 .661 & 2.364 .840 & 2.610 .079 & $0,1 \%$ & $10,4 \%$ \\
\hline 15 a 39 & 6.888 .644 & 6.648 .542 & 7.015 .174 & 7.527 .640 & $9,3 \%$ & $7,3 \%$ \\
\hline 40 a 44 & 6.547 .439 & 8.209 .895 & 8.108 .563 & 7.907 .640 & $20,8 \%$ & $-2,5 \%$ \\
\hline 45 a 48 & 2.792 .000 & 2.024 .945 & 1.903 .035 & 1.800 .695 & $-35,5 \%$ & $-5,4 \%$ \\
\hline 49 ou mais & 3.395 .622 & 3.108 .367 & 3.519 .039 & 3.650 .194 & $7,5 \%$ & $3,7 \%$ \\
\hline Total & 22.232 .123 & 21.854 .410 & 22.910 .651 & 23.496 .248 & $5,7 \%$ & $2,6 \%$ \\
\hline
\end{tabular}

Fonte: Microdados PNADCT/IBGE - Elaboração Própria

\section{Alemanha}

As alterações relacionadas ao tempo de trabalho na Alemanha ocorreram basicamente em dois momentos. Primeiro, no âmbito do Plano Hartz (2002 -2005) sendo a "promoção do emprego a tempo parcial nos serviços domésticos" uma das treze áreas contempladas pelas reformas" (GASKARTH, 2014, p.14). Depois, na esteira da crise global de 2008.

No primeiro momento, no contexto da segunda fase do plano Hartz, em dezembro de 2002, foram incentivadas duas modalidades de emprego para encorajar os empregadores a contratar, ampliando o escopo que antes era focado no trabalho doméstico. Enquanto a primeira fase do plano Hartz focava na flexibilização das questões burocráticas do modo de contratação temporário, a segunda almejava, sobretudo, alterações no tempo das jornadas. Destaca-se que a legislação que regularizou os contratos a prazo fixo foi a mesma que inseriu no mercado de trabalho formal os contratos de meio expediente (até zo horas semanais). Este processo foi responsável por extinguira lei de promoção de emprego, Beschäftigungsförderungsgesetz, legislação trabalhista alemã elaborada em 1996. O Hartz II foi responsável por legitimar os chamados subempregos. Dentre as alterações, este plano viabilizou contratos de trabal ho com jornadas limites de 15 ou 30 horas semanais e um teto salarial de 450 euros. Os empregos cuja jornada de trabalho obedecia a um teto de 15 horas semanais foram denominados "minijobs". Detalhe que a maioria destes cargos remuneravam entre 325 e 400 euros, pois, acima desse valor, o empregador passava a pagar taxas maiores de seguridade social. Este plano reduziu consideravelmente as obrigações contratuais do capitalista. Por exemplo, antes o contratante tinha o dever de pagar $22 \%$ do valor equivalente ao salário em taxas de seguridade. Posteriormente, esta taxa caiu para 10\%. (GASKARTH, 2014). Além dos "minijobs", surgiram os 
"midjobs". Estes apresentavam maiores salários, 400 a 800 euros, e, também, maiores jornadas de trabalho. Assim como os 'minijobs', os "midjobs" foram responsáveis por reduzir a taxa de seguridade paga pelos empregadores para apenas $4 \%$ do respectivo salário bruto. Apresentam um caráter acentuado de gênero e elevada faixa etária, com as mulheres correspondendo a $73 \%$ dos miniJobse $84 \%$ dos midiJobs, com uma média de idade de respectivamente 47 anos e 42 anos, servindo de complemento de renda ou segundo emprego(GASKARTH, 2014).

Os regimes de trabalho de curta duração foram uma das principais medidas utilizadas na Alemanha para fazer frente à crise entre 2008 e 2013, bem como adaptações do tempo de trabal ho e redução do tempo de trabalho como medida temporária. Em 2013, o período hábil para trabalho de curta duração havia sido estendido de seis meses para um ano (LANG, CLAUWAERT, SCHÖMANN, 2013). O estado chegou a subsidiar até $67 \%$ dos salários líquidos de trabalhadores em empregos de curta duração por 6-12 meses em 2012 e 24 meses no auge da crise, em 2009 (CLAUWAERT, SCHÖMANN e BÜTTGEN, 2016a).

De acordo com Clasen, Clegg e Kvist (2012), ainda como resposta à crise, um terço das empresas alemãs estabeleceu uma espécie de banco de horas em que a empresa reduzia temporariamente o número de horas trabalhadas na semana, transformando-as em crédito para quando houver necessidade de aumento do tempo trabal hado.

Portanto, no que toca ao tempo de trabalho, a saída da crise na Alemanha se deu pela ampliação e desenvolvimento de esquemas de trabal ho de curta duração. O uso do trabalho de curta duração durante o período de 2002-2003 (plano Hartz) foi menor do que durante a crise econômica (LANG, CLAUWAERT e SCHÖMANN, 2013).

Boulin e Cette (2013) endossam o argumento de que a estabilidade da taxa de desemprego na Alemanha, durante a crise, se produziu a partir de uma combinação de diferentes instrumentos, quais sejam: i) a diminuição nas horas extraordinárias; ii) o uso de banco de horas (Arbeitszeitkonto); o uso de reduções no tempo de trabalho subsidiadas pelo Estado (Kurzarbeit) e, por fim, a redução temporária de salários e tempo de trabalho implementadas via acordos coletivos. Como se verá adiante, esses instrumentos foram o caminho inverso do tomado por países como a França, por exemplo, que apostaram em medidas de extensão de jornada como saída da crise. Boulin e Cette (2013) consideram que se pode falar em dois modelos diferentes, no entanto, considerando as diferentes estruturas de mercado de trabalho nos distintos países, não se pode concluir sobre a superioridade da estratégia alemã. 
Espanha

A Espanha passou por uma série de reformas coordenadas principalmente entre 2010 e 2015. Muitas das medidas relacionadas a tempo de trabal ho foram focadas no desembaraço da flexibilidade interna quantitativa (variações nos horários de trabalho, e.g. extensão da jornada ou diminuição, bem como sua distribuição ao longo de um dado período) a partir dos interesses da empresa. Conforme organizaram Clauwaert, Schömann e Büttgen (2016C), em 2010, houve duas medidas para incentivar acordos coletivos que promovessem a flexibilidade interna e cortes no tempo de trabalho:

i) Garantia de maior liberdade para as empresas alterarem as condições de trabalho em termos de horas, tempo de trabalho, mobilidade funcional e geográfica. Em caso de desacordo, prevê-se um sistema de arbitragem sem recorrer a processos judiciais.

ii) Empregadores podem reduzir o horário de trabal ho de 10\% a 70\%, com compensação de desemprego proporcional aos trabalhadores. Anteriormente, a cobertura do subsídio de desemprego só era aplicada se as horas de trabalho fossem reduzidas em pelo menos um terço. No caso de se comprometerem a fornecer treinamento aos funcionários afetados, as empresas receberiam bônus de 50\% a 80\%. Ademais, estabeleceu-se um novo padrão para os benefícios de trabalho a curto prazo, baseados em horas e não mais em dias de folga.

No ano seguinte, pelo Decreto-Lei Real 07/2011, intensificam-se as medidas visando à possibilidade de aumento do controle das empresas quanto ao tempo de trabalho por meio de acordos coletivos, não apenas para postos de curto prazo: a principal mudança do referido decreto mudança foi na hierarquia da negociação coletiva. Pelo decreto, os acordos coletivos da empresa passam a preceder os acordos coletivos provinciais, salvo se um acordo nacional, setorial ou regional determine o contrário. É uma mudança significativa, uma vez que os acordos provinciais cobriam $70 \%$ dos negócios (CLAUWAERT, SCHÖMANN e BÜTTGEN, 2016c).

Os autores apontam, ainda, que, em fevereiro de 2012, pela Lei 3/2012, três novas medidas em relação à flexibilidade no tempo de trabal ho foram introduzidas:

i) Abriu-se a possibilidade de funcionários em tempo parcial ou meio período poderem trabalhar horas extraordinárias, com limite anual de 80 horas a ser aplicado para 0 emprego a tempo parcial numa base proporcional. A lei já previa, e não elimina, horas extras especiais para esta modalidade de emprego, as chamadas "horas complementarias" estão condicionadas a certos requisitos formais e limitações numéricas. 
ii)

As empresas passam a poder distribuir, conforme sua conveniência operacional ou conjuntural, até $5 \%$ das horas anuais de trabalho durante o ano, regra que pode ser aplicada antes das negociações sobre um novo acordo coletivo.

iii) As empresas passam a prescindir de permissão da autoridade trabalhista para reduzir temporariamente as horas de trabalho ou para instituir demissões temporárias. Com a condição de apenas seguir o procedimentolegal de consulta coletiva com representantes dos funcionários, as empresas são autorizadas a implementar demissões temporárias e reduzir temporariamente entre $10 \%$ e $70 \%$ por cento das horas de trabalho dos funcionários.

A reforma tinha, ainda, outro objetivo, que era menos explícito: a desvalorização dos salários. O objetivo final era que a Espanha recuperasse parte de sua competitividade perdida durante a crise, à base da redução de salários, já que não poderia realizar uma desvalorização da moeda, por estar inserida na União Europeia. Este objetivo foi alcançado. Em 2011, a média salarial era de 25.999,97 euros anuais, diminuindoem quase 800 eurosem 2015.

Além disso, outra medida estabeleceu que todos os funcionários com, pelo menos, um ano de serviço devem receber uma licença remunerada anual de 20 horas para treinamento relacionado ao trabalho, que pode ser acumulada ao longo de três anos. Para completar, com o objetivo declarado de facilitar a flexibilidade interna, determinou-se que acordos a nível de empresa têm precedência sobre acordos em instâncias superiores, extinguindo uma das condições que haviam sido postas no ano anterior de "salvo se um acordo setorial determine o contrário". Além disso, permitiu às empresas descumprir (opt-out) acordos anteriores no caso de apresentarem prejuízos por mais de dois trimestres (CLAUWAERT, SCHÖMANN e BÜTTGEN, 2016c)

As novas formas de estar conectado tornaram o começo e o fim da jornada de trabalho mais difusos do que nunca, e, por conseguinte, obscureceram as fronteiras entre a vida pessoal e profissional. Assim, seguindo o exemplo da França (vide abaixo), a Espanha implementou, em dezembro de 2018 , uma lei que regulamenta, entre outras coisas, o direito à desconexão digital no local de trabal ho. Pela Ley Orgánica 3/2018 (Protección de Datos Personalesy garantía de los derechos digitales), no seu artigo 88:

1. Os trabalhadores do setor privado e funcionários públicos terão o direito à desconexão digital, a fim de garantir, fora do tempo de trabalho legal ou convencionalmente estabelecido, o respeito ao seu tempo de descanso, licença e férias, bem como à sua privacidade pessoal e familiar.

2. As modalidades de exercício deste direito devem estar de acordo com a natureza e o propósito da relação de trabalho, devem reforçar o direito à conciliação do trabalho e da vida pessoal e familiar e devem estar sujeitos às disposições da negociação coletiva ou, na sua falta, conforme acordado entre a empresa e os representantes dos trabalhadores. 
3. O empregador, depois de ouvir os representantes dos trabalhadores, elaborará uma política interna para os funcionários, incluindo aqueles em cargos de gerência, na qual eles definirão as modalidades para o exercício do direito à desconexão e ações de treinamento e conscientização do pessoal sobre a utilização razoável das ferramentas tecnológicas que evitam o risco de fadiga informática. Em particular, o direito à desconexão digital será preservado em casos de realização total ou parcial de trabalho remoto, bem como no domicílio do funcionário vinculado ao uso de ferramentas tecnológicas para fins de trabalho (BOE, 2018, p. 119838).

Cabe ressaltar que já estavam em vigor acordos a nível de empresa que versavam sobre essa matéria. É o caso da seguradora AXA, primeira empresa do país a incluir o direito de seus funcionários de não atender chamadas ou e-mails fora do seu horário de trabal ho, "salvo causa de força maior ou circunstâncias excepcionais", emjulho de 2017(AGUILAR, 2017).

\section{França}

Desde a década de 70, a França vinha promovendo alterações no âmbito do tempo de trabalho. Até a eclosão da crise global de 2008, a tendência era mais a favor das reduções do tempo de trabalho ${ }^{6}$ sob o argumento de que reduzir as horas de trabalho semanais era uma forma de criar novos empregos. Por exemplo, as Leis Aubry em 1998 e 2000, que trouxeram o tempo de trabalho semanal estatutário de 39 para 35 horas (ou 1.600 horas anuais) (LANG, CLAUWAERT, SCHÖMANN, 2013).

No entanto, especialmente depois da crise, a França implementou uma série de medidas que tinham por corolário o aumento do tempo de trabalho, mas que também se apoiavam ou davam seguimento a medidas anteriores. Por exemplo, a Loi en faveur du Travail, de l'Emploi et du Pouvoir d'Achat (TEPA), que vigorou de 2007 a 2012. Essa lei, promovida pelo slogan "travailler plus pour gagner plus", incentivou o uso de horas extras através da exclusão da tributação tanto para empregados (não taxação) e empregadores (desconto nas contribuições sociais). Uma pesquisa conduzida pelo Departamento de Trabalho da França mostrou que $2 / 3$ dos funcionários em tempo integral tinham feito horas extras em 2009 (BOULIN e CETTE, 2013). Um balanço posterior da medida mostraria que o aumento nas horas extras veio concomitante com uma diminuição no tempo de trabalho fora do tempo extra, de modo que a medida, além de não ajudar na geração de empregos, também contribuiu para fragilizar as finanças públicas (AFP, 2018).

Em 2013 foi firmado um acordo chamado "sécurisation del'emploi" por organizações patronais e três grandes sindicatos que objetivava flexibilizar (diminuir) tempo de trabalho e salários sob a

\footnotetext{
6 Apesar do Decreto 2002-1257 de 15/10/2002, que aumentou o limite máximo de horas extras, passando de
} 130 horas anuais para 180 horas, e que, em 2004, passaria para 220 horas extras). 
justificativa de garantir os empregos. Por meio do seu $18^{\circ}$ abria a possibilidade de as empresas, em caso de graves dificuldades a curto prazo, chegarem a um acordo com os representantes dos trabalhadores no ajustamento do tempo de trabalho, organização do trabal ho e salários para evitar demissões (BOULIN e CETTE, 2013).

Em 2014 foi estabelecido que o tempo mínimo de trabalho a tempo parcial seria de 24 horas por semana, com a possibilidade de o trabalhador requisitar, individualmente, um contrato de trabalho inferior a 24 horas por semana. Acordos setoriais também poderiam fornecer derrogações ao mínimo de 24 horas (CLAUWAERT etal, 2016).

A Lei n. 2016-1088 (reforma trabalhista de 2016 ou, ainda, Lei El Khomri) instituiu que, por meio de um acordo de empresa (e não apenas por convenção coletiva como previsto em 2008), era possível realizar ajustes na jornada de trabalho (vale lembrar que a Lei n. 2008-789 de 20/8/2008 havia autorizado a realização de ajustes na jornada de trabalho mediante convenção coletiva). A Lei El Khomri aumentou o limite máximo das horas extras, sendo possível chegar a uma jornada semanal de 48 horas ou até 60 horas, em casos excepcionais, para os quais deve haver aprovação da inspeção do trabalho. Redefiniu, ainda, o pagamento da taxa de majoração referente a horas extras trabalhadas ( $25 \%$ nas 8 primeiras horas e $50 \%$ depois deste período). Implementou a mudança no período de referência para os cálculos do tempo de trabalho de um para três anos. Também previa que acordos a nível de empresa poderiam incluir nos cálculos de horas de trabalho efetivas o tempo necessário para trocar de uniforme, bem como descumprir acordos anteriores sobre perío dos de repouso diários, determinar períodos de pausa (mínimo de 20 minutos) e dias úteis (com exceção de 1 de Maio), implementar períodos de plantão, recorrer a trabalhos esporádicos irregulares e até regular certos aspectos do trabalho a tempo parcial (CLAUWAERT et al, 2016). Na França, o contrato intermitente havia sido criado em 2000, mas sua utilização dependia de negociação coletiva e era restrita a setores caracterizados por atividades sazonais; com a reforma de 2016-2017, passou a ser autorizado mediante simples negociação coletiva ou acordos de empresa e, até dezembro de 2019, dispensam estes requisitos para atividades sazonais.

A Lei El Khomri ainda traz uma inovação que, mais tarde, seria copiada pela Espanha, como se viu acima. Trata-se da disposição sobre a obrigatoriedade de negociação do direito de se desconectar. Representantes dos trabal hadores, em acordos com a empresa, passariam a ser capazes de determinar regras para o direito de funcionários para desconectar do trabalho, a fim de garantiro respeito aos tempos de descanso, licença e vida pessoal (CLAUWAERT et al, 2016).

Por fim, o artigo 4 da ordonnance $n^{\circ} 2017-1386$, institui que, na ausência de acordo de empresa ou convenção coletiva (acordo de ramo/categoria):i) o contrato de trabal ho pode fixar a remuneração do tempo de pausa; ii) o contrato de trabalho pode estabelecer contrapartidas ao tempo gasto pelo trabalhador para vestir-se e despir-se mencionadas no artigo ; iii) essas contrapartidas podem ser 
determinadas pelo empregador após uma consulta ao comitê de empresa ou aos delegados de pessoal (na existência destes).

Para os outros domínios das relações de trabalho, o acordo de empresa prevalece sobre a convenção coletiva. Deste modo, por exemplo, a reforma trabalhista de 2017 institui a primazia do acordo de empresa no tocante à remuneração (prêmios por tempo de serviço, prêmio de férias, indenizações por demissão, indenização por aposentadoria, majoração pelo trabalho noturno, majoração do trabalho aos domingos e em feriados).

Ainda no tocante à remuneração, a partir das reformas de (2016-2017), as horas suplementares têm acréscimo de $25 \%$ nas 8 primeiras horas e 50\% depois deste período ( $L$ 3121-22), contudo, existe a possibilidade de derrogação desta regra mediante acordo por empresa ou convenção coletiva, desde que respeitado o piso de 10\% de acréscimo à hora extra trabalhada.

Portugal

As alterações recentes quanto ao tempo de trabalho em Portugal foram relativamente mais modestas do que em países como Espanha e França. Com o Código de Trabalho de 2009, a jornada de trabalho poderia ser estendida por 4 horas diárias, sem exceder o total de 60 horas por semana, dentro do limite de 200 horas por ano, e deveriam ser acordadas coletivamente e aplicadas exclusivamente aos trabalhadores cobertos pelos acordos. A nova regulação, implementada pela lei 23/2012, ao aditar o artigo 208\%-B no código de trabalho, permitiu ao empregado estender o banco de horas acordado coletivamente para todos os empregados dentro de uma seção ou unidade, desde que $60 \%$ dos empregados fossem cobertos pelo acordo coletivo ou que $75 \%$ deles concordassem.

A lei também introduziu o banco de horas individual, depois do aditamento do artigo 208०-A, ao código de trabalho. $\mathrm{O}$ banco de horas individual poderia ser acordado entre um patrão e um empregado, sendo permitida a extensão da jornada de trabalho para duas horas diárias, com o máximo de 50 horas por semana, dentro de um limite de 150 horas por ano.

O tempo acumulado no banco pode ser compensado de três formas: uma redução equivalente najornada de trabalho, um aumento no período de férias, ou pagamentos em dinheiro. Antes, não pera possível compensar com o aumento de férias. Além disso, reduziu a compensação por hora-extra de trabalho pela metade, de 50\% para 25\% do salário para a primeira hora e de $75 \%$ para $37,5 \%$ para cada hora subsequente, nos termos da alteração do artigo $268^{\circ}$.

No que tange ao intervalo de descanso, antes das mudanças, o trabalhador tinha o direito a um intervalo de descanso entre 1 e 2 horas, de forma que ele não trabal hasse 5 horas seguidas. A lei 23/2012 trouxe uma alteração no artigo $213^{\circ} \mathrm{e}$, agora, o trabal hador com jornada de trabal ho superior a 10 horas pode trabal har por 6 horas seguidas antes do intervalo de descanso. 
Em relação à compensação de trabalho de curto-período, com a Lei 23/2012, caso o empregador deseje implementar esquemas de trabalho de curto-período, como a redução temporária da jornada de trabalho, o aviso prévio aos trabalhadores foi diminuído de 10 para 5 dias, com a possibilidade de começar imediatamente se o conselho de trabal hadores concordar, seguindo a mudança no artigo $301^{\circ}$ do código de trabalho. A mudança no mesmo artigo também prevê que o órgão representativo dos trabal hadores não mais poderia se opor a uma extensão do esquema, desde de que o empregador siga os procedimentos de comunicação. A reforma também protegeu os trabalhadores de demissão logo após o fim do esquema (artigo $303^{\circ}$ ) e garantivaos trabal hadores um aumento no pagamento, caso o trabal hador tenha entrado em al gum treinamento durante o período (art. $\left.305^{\circ}\right)$.

Por fim, houve as reduções nos feriados e finais de semana prolongados. Quatro feriados públicos foram abolidos a partir de 1 de janeiro de 2013, com a lei 23/2012, ao alterar o artigo $234^{\circ}$, saindo de 13 para 9 feriados por ano. A lei 8/2016 alterou novamente o artigo, adicionando outra vez os quatro feriados. Antes da lei, trabal hadores que não faltaram ou que tiveram um número menor que três de faltas justificadas durante o ano anterior, teriam direito de 1 a 3 dias extras de férias anuais, de acordo como artigo $23^{\circ}$. Depois da lei, o direito foi revogado, e foi incluída, no artigo $25^{\circ}$, uma punição para faltas injustificadas. Caso o trabalhador faltasse sem justificativa em uma segunda, em uma sexta ou no dia imediatamente seguinte ou anterior a um feriado, perderia dois dias de salários.

Junto com o congelamento das extensões dos acordos coletivos, os salários do setor público foram ou congelados ou cortados, o salário mínimo nacional foi congelado e a compensação por tempo extra foi reduzida. Para além disso, o governo suspendeu, por um período de dois anos, todas as cláusulas de acordo coletivos e contratos de trabalho a respeito de compensações por hora-extra que foram assinadas antes de 1 de agosto de 2012. Com a Lei 64-A/2014, a suspensão foi estendida para 31 de dezembro de 2014 .

Em julho de 2019, o Conselho Econômico e Social de Portugal lançou um acordo entre entidades sindicais patronais e de empregados intitulado "Combater a precariedade e reduzir a segmentação laboral e promover um maior dinamismo na negociação coletiva" (CES, 2019). O documento vai na contramão das medidas tomadas nos momentos mais intensos da crise. No que diz respeito especificamente ao tempo de trabalho, a questão do banco de horas é o que consta de mais relevante. Ou seja, não propõe novas regulamentações ou restrições à discricionariedade das empresas, limita-se a reverter al gumas das alterações mencionadas acima, com o objetivo de reduzir a individualização das relações trabalhistas: eliminar o banco de horas individual e os grupais baseados em acordos individuais, embora mantendo aqueles grupais com base em outros acordos grupais, mediante autorização dos trabalhadores. 
Reino Unido

Desde antes da crise, os sucessivos governos do Reino Unido já vinham introduzindo reformas substanciais no mercado de trabalho, principalmente em relação ao acesso à justiça. No que toca ao tempo de trabalho, ocorre, de forma mais acentuada, em 2013 e 2015, com as seguintes medidas, de acordo com Clauwaert, Schömann e Büttgen, (2016b):

Em 2013 houve a ampliação, a todos os funcionários, do direito de solicitar um trabalho flexível após 26 semanas na empresa. A possibilidade de pedir aos empregadores um horário de trabalho flexível, teletrabalho, etc. só existia para pais de crianças com até 16 anos (ou 18 anos, no caso de deficientes). A lei, no entanto, não oferece garantias de que o empregador deve acatar o pedido.

Em 2015 foram introduzidas mudanças para proibir cláusulas de exclusividade em contratos de zero hora (trabalho intermitente) para funcionários que se enquadrassem em um baixo patamar de remuneração e horas de trabalho semanais. Ou seja, como contrapartida do estabelecimento de uma relação de exclusividade, o empregador deve garantir uma renda semanal ao trabalhador, definida pela multiplicação do número acordado de horas pelo salário mínimo nacional adulto. № entanto, a cláusula de exclusividade não é proibida se o empregador fornecer uma remuneração de pelo menos 20 libras por hora.

No caso do trabal ho excedente, os empregadores não precisam necessariamente remunerar as horas extras; a única limitação é que a remuneração por hora do trabalhador não pode ser abaixo do salário mínimo nacional. Em outros casos, o contrato de emprego de cada trabalhador deve esclarecer sobre a remuneração das horas extras e como elas devem ser compensadas.

\section{Evidências empíricas sobre a distribuição da jornada e da remuneração}

Nesta subseção, por fim, mostra-se alguns dados relativos à distribuição da jornada e o comportamento das remunerações nos paísesselecionados. Os países selecionados compreendema Alemanha, Espanha, França, Portugal e Reino Unido, sendo que os dados cobre mo período de 2000 a 2017, assim, contribuindo para o entendimento dessas duas dimensões principalmente com o arrefecimento das modificações nas legislações no pós-crise de 2008.

A jornada de trabalho e a subutilização do trabalhador

O gráfico 3 traz o percentual dos trabal hadores que, semanalmente, laboram entre 35 e 48 horas, onde se encontram, conforme a figura 1, a maior parte das jornadas normais estatutárias. Espanha e Portugal, bem como Alemanha e França apresentam entre si distribuições similares para 
esta faixa (por volta de $60 \%$ para o primeiro par e $52 \%$, para o segundo). O Reino Unido destoa, sendo o único país analisado onde menos da metade da força de trabalho não labora dentro do estrato considerado como "semana padrão".

Gráfico 3 - Empregados que trabal ham entre 35 e 48 horas por semana (\%)

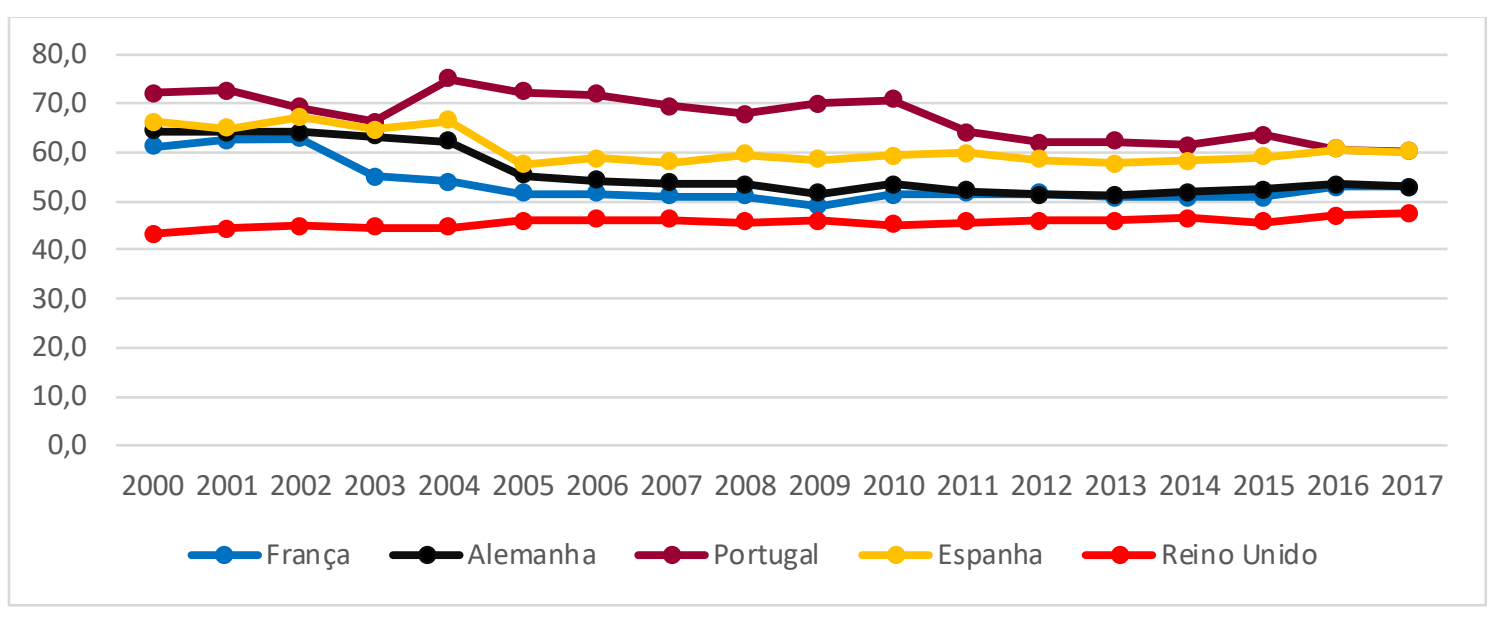

Fonte: ILOSTAT

O gráfico 4 ilustra o percentual de trabalhadores que perfazem uma jornada semanal de menos de 35 horas por semana para cada país analisado. França, Alemanha e Reino Unido apresentam números semelhantes, pouco acima dos 40\%. Portugal e Espanha, mais abaixo, com 28,8\% e 32,6\%, respectivamente.

Gráfico 4- Empregados que trabalham menos de 35 horas por semana (\%)

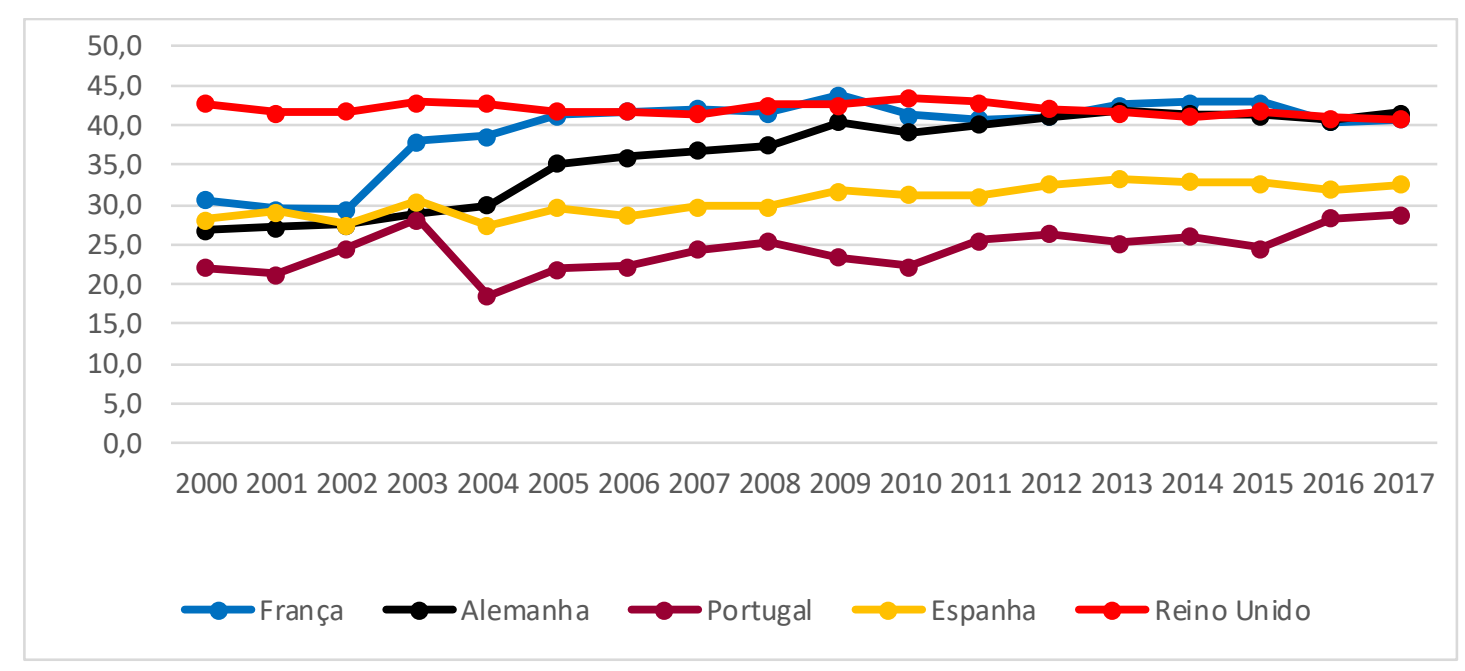

Fonte: ILOSTAT 
Um dos expedientes mais utilizados durante a crise e que está relacionado com o tempo de trabalho é o fomento de formas de emprego de período curto (ou tempo parcial), que, como citado acima, oferece remuneração relativamente baixa, menor cobertura de benefícios e um maior grau de instabilidade. Assim, muitos trabalhadores se engajam nessa modalidade por não haver opção de contratos típicos. Por outro lado, esta é uma modalidade que atende àqueles que já possuem um emprego "típico" e buscam um complemento na renda. O gráfico 5 mostra que, em países como Reino Unido (14,1\%) e Alemanha (11,1\%), os percentuais de trabalhadores a tempo parcial involuntários são relativamente baixos, não havendo grandes variações desde o começo da década de 2000 . No caso da Alemanha nota-se um aumento intenso do percentual logo após a segunda fase do plano Hartz (2003), chegando a superar os 20\%, para, de 2010 em diante, apresentar um recuo, chegando a 11,1\% em 2017.

França, Portugal e Espanha, por sua vez, apresentam uma alta proporção de involuntários entre os trabalhadores a tempo parcial. O caso mais dramático é o da Espanha, onde, desde 2004, houve um crescimento exponencial de involuntários, que fechov em 64,4\% em 2017.

Gráfico 5 - Percentagem de trabal hadores a tempo parcial involuntários em \% do emprego a tempo parcial

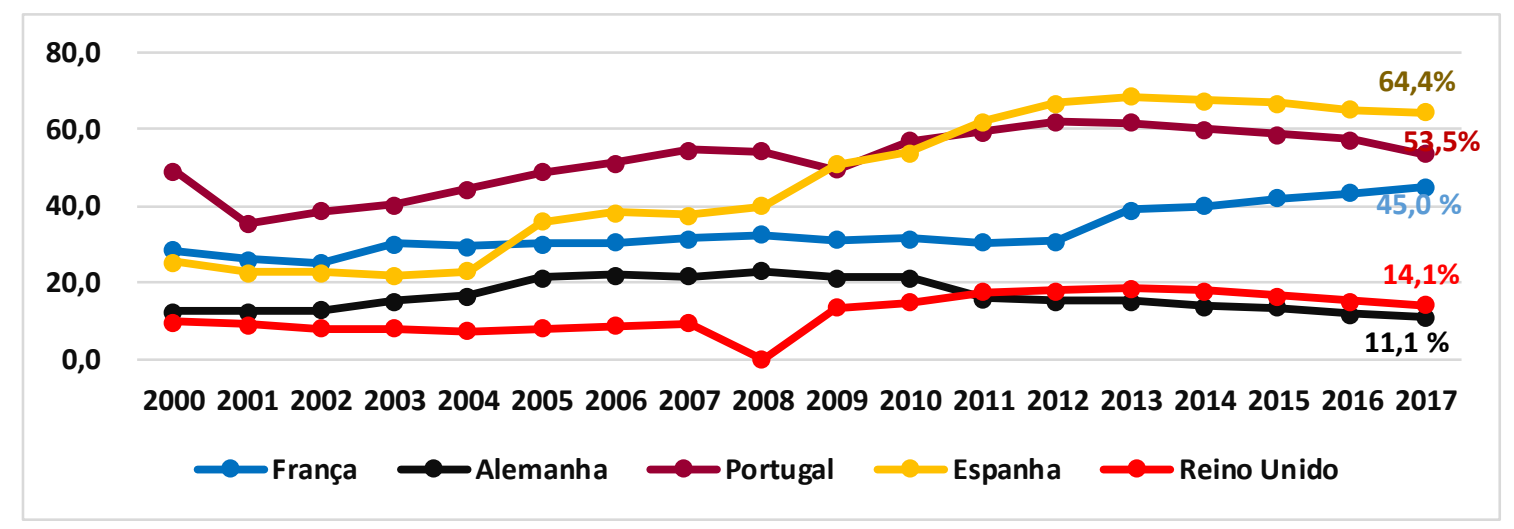

Nota: para Reino Unido não houve dado no ano de 2008.

Fonte: OECD

Lang, Clauwaert e Schömann (2013) avaliam que a opção por essa modalidade como forma de sair da crise pode aumentar a segmentação do mercado de trabalho, dado que os esquemas de trabalho de curta duração geralmente são apoiados por fundos de seguro-desemprego, comprometendo recursos para políticas ativas do mercado de trabalho.

Desde o início dos anos 2000, já se configura uma tendência internacional comum de reduzir as horas de trabalho, como estabelecido pela Diretiva 2003/88/ CE, artigo 6.0-B da Comissão Europeia. Pela mesma, recomendou-se que o número de horas semanais de trabalho não deve exceder, em média, 48 horas por cada período de sete dias, incluindo horas extraordinárias (durante 
um período de referência de três meses) (ANXO e KARLSSON, 2019). No entanto, observa-se que, contrariamente a esta Diretiva, entre 2003 e 2005, em estados membros como Espanha e Alemanha há um aumento significativo na proporção de empregados trabal hando mais de 48 horas por semana, voltando a cair nos anos subsequentes (GRÁFICO 6). Dentre os países considerados, o Reino Unido é o que apresenta os maiores níveis.

Gráfico 6 - Empregados que trabal ham mais de 48 horas por semana (\%)

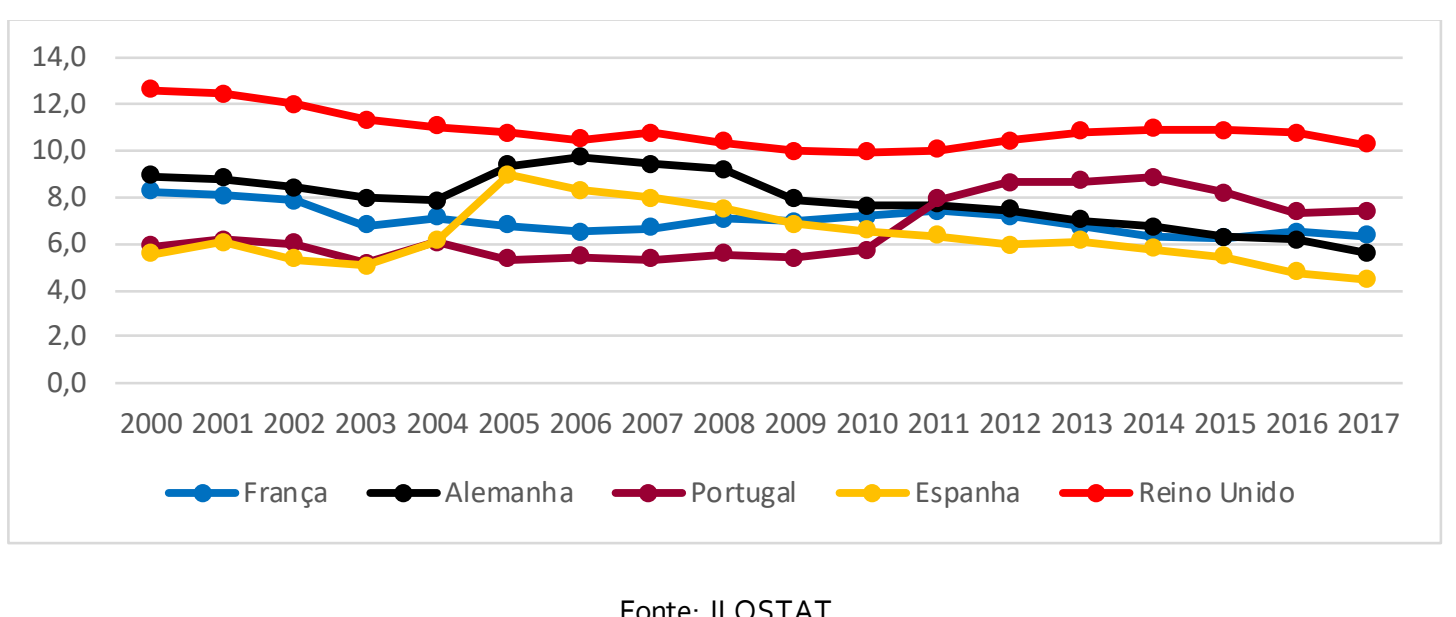

O gráfico 4 mostrou que o Reino Unido também é um dos que contam as maiores proporções de trabalhadores que laboram menos de 35 horas semanais, ou seja, esses números dão suporte à hipótese de bifurcação dajornada de trabalho no país.

Independentemente da amplitude das reformas (se a alterações ocorrem sobre códigos inteiros ou de maneira fragmentada), o resultado é a deterioração dos direitostrabalhistas individuais e coletivos, promovendo precariedade e reduzindo a proteção ao trabal hador, de maneira geral e no ambiente de trabalho (CLAUWAERT e SCHÖMANN, 2012).

A trajetória da remuneração: estagnação e rebaixamento salarial

Quando passamos para a análise da questão salarial, observa-se uma correspondência entre as reformas e a estagnação ou queda subsequente dos salários por trabalhador, refletindo diminuições nas participações dos salários em relação ao produto interno bruto em cada país. Isso ocorre geral mente porque tais reformas fazem parte de medidas de austeridade, essas com o intuito de combater recessões econômicas ou situações de crise, como vivenciadas em 2008, e cada vez mais recorrentes, em âmbito mundial. 
Como podemos visualizar na Tabela 1, segundo dados da OCDE (por paridade de poder de compra), os valores dos salários médios anuais por empregado em tempo integral ${ }^{7}$ apresentam um comportamento de estagnação a partir dos anos 2000, especificamente na Alemanha até 2010, seguido pela Espanha e Portugal, cujo comportamento ocorreu em todo o período pesquisado. No período entre 2010 e 2017, no caso da Espanha e Portugal, os salários médios são inferiores aos de 2009, apresentando uma trajetória de diminuições sucessivas e sem a perspectiva de recuperação numfuturo próximo.

Tabela 1 - Salário médio anual - Em preços constantes de 2017, em US\$ dólares de PPC (Paridade de poder de Compra) de 2017-2000/2017

\begin{tabular}{cccccc}
\hline Ano & França & Alemanha & Portugal & Espanha & Inglaterra \\
\hline \hline $\mathbf{2 0 0 0}$ & 36.341 & 41.873 & 26.383 & 36.327 & 38.110 \\
$\mathbf{2 0 0 1}$ & 36.593 & 42.291 & 26.498 & 36.320 & 40.036 \\
$\mathbf{2 0 0 2}$ & 37.583 & 42.513 & 26.485 & 36.588 & 40.690 \\
$\mathbf{2 0 0 3}$ & 37.899 & 42.457 & 26.416 & 36.489 & 41.771 \\
$\mathbf{2 0 0 4}$ & 38.520 & 42.454 & 26.462 & 36.112 & 42.751 \\
$\mathbf{2 0 0 5}$ & 38.983 & 42.380 & 26.310 & 36.322 & 42.630 \\
$\mathbf{2 0 0 6}$ & 39.413 & 42.415 & 25.740 & 36.185 & 43.627 \\
$\mathbf{2 0 0 7}$ & 39.578 & 42.342 & 25.921 & 36.659 & 44.897 \\
$\mathbf{2 0 0 8}$ & 39.513 & 42.610 & 25.837 & 38.134 & 43.724 \\
$\mathbf{2 0 0 9}$ & 40.732 & 42.779 & 27.031 & 40.717 & 44.465 \\
$\mathbf{2 0 1 0}$ & 41.548 & 42.970 & 26.927 & 40.018 & 44.521 \\
$\mathbf{2 0 1 1}$ & 41.472 & 43.703 & 26.287 & 39.451 & 43.370 \\
$\mathbf{2 0 1 2}$ & 41.759 & 44.202 & 25.151 & 38.328 & 43.105 \\
$\mathbf{2 0 1 3}$ & 41.986 & 44.736 & 25.668 & 38.416 & 43.154 \\
$\mathbf{2 0 1 4}$ & 42.403 & 45.421 & 25.217 & 38.422 & 42.782 \\
$\mathbf{2 0 1 5}$ & 42.731 & 46.409 & 25.164 & 39.339 & 43.152 \\
$\mathbf{2 0 1 6}$ & 43.221 & 47.097 & 25.362 & 39.196 & 43.713 \\
$\mathbf{2 0 1 7}$ & 43.755 & 47.585 & 25.367 & 38.507 & 43.732 \\
\hline
\end{tabular}

Fonte: OCDE, elaboração própria.

No caso alemão, após o período de estagnação dos salários, as políticas de austeridade foram flexibilizadas e propiciaram um aumento de $11 \%$ dos salários entre 2009 e 2017 , potencializado pela introdução do salário mínimo no país, a partir de 2015. Já no Reino Unido, o salário médio aumentou 34\% entre 1997 e 2007, também pela adoção do salário mínimo, mas, nos anos subsequentes, atingiu valores abaixo do patamar de 2007. Vale notar que, de 2004 a 2011, o Reino Unido apresentou um salário médio superior ao alemão, mas, a partir de 2012, a Alemanha volta a ter um salário médio maior e se distancia nos anos posteriores.

7 Os salários médios anuais por empregado dependente, do equivalente a tempo inteiro, são obtidos dividindo o total da conta salarial baseada nas contas nacionais pelo número médio de empregados no total da economia, que é, então, multiplicado pela taxa das horas semanais médias habituais por tempo integral empregado para todos os funcionários. 
Na França, em todo o período, constata-se um comportamento de crescimento dos salários médios anuais, mesmo diante da pressão por congelamentos e reduções salariais. Tal fato pode ser explicado pelo poder de reação dos sindicatos franceses, que conseguem sustentar o processo de elevação do salário mínimo, fator que condiciona a manutenção dos patamares da participação dos salários e sua aproximação dos salários médios alemães e ingleses.

Quando se analisa a participação dos salários no PIB, segundo dados da ILOSTAT, constatase um aumento da desigualdade entre capital e trabalho, sendo que, na Alemanha, a participação dos salários no PIB, entre 2003 e 2007, cai ao seu menor nível, ao patamar de 53,7\% abaixo dos 60,4\% atingido no período da reunificação. Na Espanha, entre 2012 e 2018, esse indicador também atinge $53,7 \%$, que corresponde ao menor nível da série histórica com início em 1991, cujovalor era de 62,9\%.

No Reino Unido, a participação dos salários cai de 56,7\%, em 1991, para 53\%, em 1997, na esteira do período de austeridade da Era Thatcher, tendo uma mudança de trajetória com a introdução do salário mínimo e, consequentemente, a elevação da participação dos salários no PIB para 58,3\% em 2007. A França é uma exceção neste grupo de países, já que, após a reforma, não sofreu uma queda da participação dos salários em relação ao PIB, oscilando entre 61\% e 63\% em todo o período.

Destarte, observamos que a não unilateralidade das mudanças provocou impactos em direções opostas nos países pesquisados, seja diante de iniciativas protetivas nas legislações, por exemplo, pela introdução do salário mínimo, no caso inglês e alemão, ou pelo seu aumento diante da pressão dos trabalhadores, no caso francês, possibilitandoaumentos dos salários médios, como pela estagnação e queda salariais derivadas das reformas trabalhistas sem efetivas medidas protetivas.

Nas formas de contratações atípicas, em particular nos casos de tempo parcial e trabalho intermitente, a situação é ainda pior. No Reino Unido, o salário médio por hora de um trabalhador intermitente é $35 \%$ menor do que a média total dos ocupados (UK-ONS 2018a). Na Alemanha, os mini-jobs têm salário médio de €291, e quase metade recebem menos do que o salário mínimo hora (contra $5 \%$ dos contratos típicos). Um quarto das pessoas cujo principal emprego é mini-jobs sofrem com risco de pobreza segundo constatação da Comissão Europeia, em 2018.

Em 2012, cerca de 14\% de todos os empregados estavam exclusivamente em empregos sem contribuição social obrigatória e $84 \%$ dos 'mini-jobbers' recebiam salários baixos. Contratos parciais puxaram ainda mais para baixo salários hora, como no caso da Espanha (2010-2014), Portugal (20062014) e o Reino Unido (2006-2014). A diferença salarial, entre os tipos de contrato de trabalho, é perceptível quando verificamos o comportamento do salário médio por hora. Em geral, seja para os trabal hadores sobre contrato por tempo ou prazo de trabal ho, os valores dos salários médios por hora são menores do que os apresentados pelos contratos típicos, como demonstram a Tabela 2 e a Tabela 3. 
Tabela 2 - Salário médio por hora*, por tempo de trabalho (em euros de PPS)

\begin{tabular}{c|ccc|ccc}
\hline \multirow{2}{*}{ Países } & \multicolumn{3}{|c|}{ Tempo Integral } & \multicolumn{3}{c}{ Tempo Parcial } \\
\cline { 2 - 7 } & $\mathbf{2 0 0 6}$ & $\mathbf{2 0 1 0}$ & $\mathbf{2 0 1 4}$ & $\mathbf{2 0 0 6}$ & $\mathbf{2 0 1 0}$ & $\mathbf{2 0 1 4}$ \\
\hline Alemanha & 16,6 & 17,34 & 19,48 & 13,64 & 13,75 & 14,03 \\
Espanha & 11,4 & 12,56 & 13,51 & 9,55 & 10,77 & 10,37 \\
França & 14,28 & 14,8 & 16,58 & 12,59 & 13,18 & 14,36 \\
Portugal & 8,54 & 9,37 & 9,27 & 11,21 & 8,5 & 7,6 \\
Reino Unido & 18,7 & 17,55 & 16,82 & 13,33 & 12,3 & 11,68 \\
\hline \hline
\end{tabular}

* Industria, construção e serviços (exceto administração pública, defesa e segurança social obrigatória). Fonte: Eurostats.

Outro aspecto a destacar, condiz com o aumento da diferença entre os salários médios por hora nas duas formas de contratação. Percebemos que o valor do tempo parcial diminui ao longo do período em relação ao de tempo integral. Por exemplo, em 2006, na Alemanha, o salário médio por hora correspondia a $82 \%$ do salário auferido nos contratos de tempo inte gral, caindo para $72 \%$ no ano de 2014. Este movimento também condiz com o apresentado pelos demais países selecionados.

Tabela 3 - Salário médio por hora, por prazo de trabalho (em euros de PPS)

\begin{tabular}{l|ccc|ccc}
\hline \multirow{2}{*}{ Países } & \multicolumn{3}{|c|}{ Prazo indeterminado } & \multicolumn{3}{c}{ Prazo determinado* $^{*}$} \\
\cline { 2 - 7 } & $\mathbf{2 0 0 6}$ & $\mathbf{2 0 1 0}$ & $\mathbf{2 0 1 4}$ & $\mathbf{2 0 0 6}$ & $\mathbf{2 0 1 0}$ & $\mathbf{2 0 1 4}$ \\
\hline Alemanha & 14,69 & 15,08 & 16,16 & 10,87 & 11,13 & 11,71 \\
Espanha & 9,71 & 10,48 & 11,09 & 7,7 & 8,68 & 8,99 \\
França & 12,03 & 12,38 & 14,12 & 10,48 & 10,29 & 11,51 \\
Portugal & 6,28 & 6,67 & 7,09 & 4,82 & 5,04 & 5,11 \\
Reino Unido & 13,39 & 12,48 & 12,43 & 10,76 & 9,74 & 9,7 \\
\hline \hline
\end{tabular}

* Exceto aprendiz e trainee.

Fonte: Eurostats.

Chama atenção o Reino Unido, onde ocorre uma diminuição do salário médio por hora, no período em questão, para qualquer tipo de contrato. Além disso, a região apresenta a maior diferença entre os contratos por tempo de trabalho, já que os trabalhadores em tempo parcial recebem em média um salário por hora $31 \%$ menorque os de tempo integral. Em contrapartida, a França apresenta os menores diferenciais de remuneração entre as diferentes modalidades de contratação. Outra forma de visualizarmos este fato pode ser por meio da utilização de dados que comparam as médias salariais dos vínculos em tempo parcial em equivalentes ao tempo integral. Conforme visualizamos na Tabela 4, a partir dos valores dos salários médios mensais, ainda em termos de paridade de compra, na totalidade dos países temos um valor salarial bem abaixo nos contratos com menores cargas horárias. Em 2014, a diferença entre o valor dos salários médios dos trabal hadores em tempo 
integral para os de tempo parcial corresponde a 28\% na Alemanha, 27\% na Espanha, 16\% na França e Portugal e $28 \%$ no Reino Unido.

Tabela 4 - Salários médio mensal*, por tempo de trabalho (em euros de PPS)

\begin{tabular}{l|ccc|ccc}
\hline \multirow{2}{*}{ Países } & \multicolumn{3}{c|}{ Tempo Integral } & \multicolumn{3}{c}{ Tempo Parcial ** } \\
\cline { 2 - 7 } & $\mathbf{2 0 0 6}$ & $\mathbf{2 0 1 0}$ & $\mathbf{2 0 1 4}$ & $\mathbf{2 0 0 6}$ & $\mathbf{2 0 1 0}$ & $\mathbf{2 0 1 4}$ \\
\hline Alemanha & 2.822 & 2.946 & 3.330 & 2.349 & 2.340 & 2.411 \\
Espanha & 1.923 & 2.113 & 2.277 & 1.582 & 1.739 & 1.683 \\
França & 2.282 & 2.349 & 2.659 & 1.969 & 2.020 & 2.224 \\
Portugal & 1.416 & 1.551 & 1.552 & 1.879 & 1.408 & 1.303 \\
Reino Unido & 3.129 & 2.920 & 2.806 & 2.315 & 2.132 & 2.017 \\
\hline
\end{tabular}

* Industria, construção e serviços (exceto administração pública, defesa e segurança social obrigatória.

** Em equivalentes a tempo integral.

Fonte: Eurostats.

Se a comparação entre os Contratos por tempo indeterminado (CPI) e os Contratos por tempo determinado (CPD) forem em relação à proporção de trabal hadores com baixos salários, na totalidade dos países selecionados, a proporção é muito maior entre os trabal hadores de CPD, destacando-se o caso francês, onde a proporção é de 24,06\%, perante 7,14\% para os CPI, no período de 2006 a 2014. Para os demais países, os CPDs apresentam valores próximos ao dobro referentes aos CPIs, como podemos visualizar na Tabela 5 .

\begin{tabular}{c|ccc|ccc}
\multicolumn{3}{c}{ Tabela 5 - Proporção de trabalhadores com baixos salários, (em \%) } \\
\cline { 2 - 7 } Países & \multicolumn{3}{|c}{ Prazo indeterminado } & \multicolumn{3}{c}{ Prazo Determinado* } \\
\cline { 2 - 7 } & $\mathbf{2 0 0 6}$ & $\mathbf{2 0 1 0}$ & $\mathbf{2 0 1 4}$ & $\mathbf{2 0 0 6}$ & $\mathbf{2 0 1 0}$ & $\mathbf{2 0 1 4}$ \\
\hline Alemanha & 18,98 & 20,9 & 20,04 & 38,81 & 38,03 & 37,81 \\
Espanha & 11,21 & 13,05 & 12,41 & 18,75 & 20,36 & 23,16 \\
França & 6,5 & 5,15 & 7,14 & 18,07 & 18,11 & 24,06 \\
Portugal & 17,67 & 13,95 & 9,62 & 30,22 & 22,98 & 18,96 \\
Reino Unido & 20,91 & 20,82 & 20,03 & 34,51 & 36,37 & 34,77 \\
\hline
\end{tabular}

* Exceto aprendiz e trainee.

Fonte: Eurostats.

Diante dos dados apresentados, pode-se associar as formas de subutilização da força de trabalho - de forma involuntária por parte do trabal hador - com menores patamares de remuneração, ou seja, mostram como os contratos por tempo determinado e em tempo parcial são desfavoráveis aos trabalhadores, ao impossibilitar-Ihes de exercer suas atividades por maiores períodos de tempo, e, mesmo se o fizerem, através da extensão via horas extras, os adicionais são porcentagens cada vez menores em relação ao valor das horas normais pagas em cada um dos tipos de contrato e são cada vez menores em comparação às remunerações auferidas pelos trabal hadores em tempointegral e por prazo indeterminado. 


\section{Considerações finais}

Em linhas gerais, através da caracterização das mudanças colocadas pelas reformas trabalhistas, nas dimensões do tempo de trabalho e da remuneração dos trabalhadores, observamos indícios de aumento da precarização das relações de trabalho. À luz deste entendimento, alguns aspectos podem ser destacados, tanto para uma melhor reflexão quanto em relação aos reais impactos da flexibilização no mundo do trabalho, como para vislumbrarmos trajetória futura das diversas dimensões quelhe compõe.

O primeiro aspecto a ser destacado condiz com um processo de subutilização da força de trabalho, via fracionamento da jornada e tempo de trabal ho, como mecanismo para a superação de períodos de crise na lógica do capitalismo flexível. Através do avanço de formas de contratação atípicas, essa condição se efetiva na prática, sempre combinada com um menor patamar de remuneração em relação aos contratos típicos. No caso do trabal ho intermitente, essa subutilização da força de trabalho proporciona uma polarização, entre os trabalhadores, em torno do tempo de trabalho e da remuneração, onde a inexistência de garantia de jornada e remuneração torna-se recorrente e possível.

Um segundo aspecto, relacionado com a remuneração, mostra que, a partir dos dados disponíveis no período (2000-2017), ocorre estagnação ou queda dos salários e piora da participação dos salários no PIB, em decorrência dos efeitos diretos e indiretos propiciados pelas reformas nos países selecionados. Devemos ressaltar que tais impactos não são compartilhados por todas as experiências investigadas, mas que as exceções, seja por aumentos nos salários ou adoção de medidas protetivas, condiz com políticas públicas que "amenizam" o processo de precariedade salarial, principalmente, por políticas de valorização do salário mínimo (Alemanha, França e ReinoUnido).

Além disso, os resultados esperados com a diminuição do tempo de trabalho e rebaixamento dos salários parecem não ser conclusivos, tanto para fomentar a criação de novos postos de trabal ho - pela queda do desemprego -, como para aumentar a produtividade diante de maiores fragmentações das jornadas de trabal ho ou diminuições das remunerações.

Como conclusão, reforçamos que a aposta nos contratos de trabal ho flexíveis em detrimento dos contratos típicos, cada vez mais presente nos mercados de trabalho, provoca um processo de extensão das jornadas de trabal ho conjugadas a menores remunerações, que, aos olhos do capital, representa a eliminação, ao máximo, dos tempos de não trabalho, em conjunto com a minimização dos custos trabal histas, por parte do capital. 


\section{Referências}

AFP. Revoici le "travailler plus pour gagner plus", mesure aux effets contrastes, 2018.

Disponívem em: https://www.lepoint.fr/societe/revoici-le-travailler-plus-pour-gagner-plus-mesureaux-effets-contrastes-01-09-2018-2247483_23.php Acesso em: 6 jun 2019.

AGUILAR, Ana. El derecho a desconectar del trabajollega a España. Disponível em: https://www.eldiario.es/economia/derecho-desconectar-trabajo-Ilega-Espana_o_667383461.html Acesso em: 14 mai2019.

ANTUNES, Ricardo; ALVES, Giovanni. As mutações no mundo do trabal ho na era da mundialização do capital. Educação \& Sociedade, v. 25, n. 87, p. 335-351, 2004.

ANXO, Dominique; KARLSSON, Mattias. Overtime work: a review of literature and initial empirical analysis. ILO conditions of work and employment series, No. 104, 2019 BOE. Boletín oficial del estado num 294, 2018. Disponível em:

https://www.boe.es/eli/es/lo/2018/12/05/3/dof/spa/pdf Acesso em: 14 mai 2019.

BRASIL. Lein. 13.467, de 13 de jul. de 2017. Altera a Consolidação das Leis do Trabalho (CLT), aprovada pelo Decreto-Lei no 5.452, de 1 de maio de 1943, e as Leis nos 6.019, de 3 de janeiro de 1974 , 8.036, de 11 de maio de 1990, e 8.212, de 24 de julho de 1991, a fim de adequar a legislação às novas relações de trabalho. Disponível em: http://www.planalto.gov.br/ccivil_03/_ato20152018/2017/lei/l13467.htm. Acesso em: 18 jul. 2018.

BOULIN, Jean-Yves; CETTE, Gilbert. Labour Market adjustments during teh crisis: the role of working time arrangements. Disponível em:

https://www.researchgate.net/publication/270708764_Labour_market_adjustments_during_the_cri sis_The_role_of_working_time_arrangements1 Acesso em: 15 jun 2019.

CASTEL, Robert. Metamorfoses da questão social. Petrópolis: Editora Vozes, 1998.

CES. Combater a precariedade e reduzir a segmentação laboral e promover um maior dinamismo na negociação coletiva, 2019. Disponível em: https://www.portugal.gov.pt/downloadficheiros/ficheiro.aspx?v=1f814583-a74b-4c99-b741-d8d955199d69 Acesso em:15jul. 2019.

CLASEN, Jochen; CLEGG, Daniel; Kvist, Jon. European labour Market policies in (the) crisis. ETUI working paper, 2012. Disponível em: https://www.etui.org/Publications2/Working-Papers/Europeanlabour-market-policies-in-the-crisis Acessoem: 15jun 2019.

CLAUWAERT, Stefan et al. The crisis and national labour law reforms: a mapping exercise. Country report: France, 2016. Disponível em: https://www.etui.org/Publications2/WorkingPapers/The-crisis-and-national-labour-law-reforms-a-mapping-exercise Acesso em: 28 jun 2019.

CLAUWAERT, Stefan; SCHÖMANN, Isabelle. The crisis and national labour law reforms: a mapping exercise. ETUI working paper, 2012.

CLAUWAERT, Stefan; SCHÖMANN, Isabelle; e BÜTTGEN, Nina. The crisis and national labour law reforms: a mapping exercise. Country report: Germany, 2016a. Disponívelem: https://www.etui.org/Publications2/Working-Papers/The-crisis-and-national-labour-law-reforms-amapping-exercise Acesso em: 28 jun 2019. 
CLAUWAERT, Stefan; SCHÖMANN, Isabelle; e BÜTTGEN, Nina. The crisis and national labour law reforms: a mapping exercise. Country report: United Kingdon, 2016b. Disponível em: https://www.etui.org/Publications2/Working-Papers/The-crisis-and-national-labour-law-reforms-amapping-exercise Acesso em: 28 jun 2019.

CLAUWAERT, Stefan; SCHÖMANN, Isabelle; e BÜTTGEN, Nina. The crisis and national labour law reforms: a mapping exercise. Country report: Spain, 2016c. Disponível em:

https://www.etui.org/Publications2/Working-Papers/The-crisis-and-national-labour-law-reforms-amapping-exercise Acesso em: 28 jun 2019.

DAL ROSSO, Sadi. O ardil da flexibilidade: os trabal hadores e a teoria do valor. São Paulo:

Boitempo, 2017.

DOSI, Giovanni et al. The Effects of Labour Market Reforms upon Une mployment and Income Inequalities: an Agent Based Model. ISI Growth working paper, 2016. Disponível em: < http://www.isigrowth.eu/wp-content/uploads/2016/o7/working paper 2016 23.pdf $>$ acesso em: 16 abr. 2019

ENGELS, Friedrich. A situação da classe trabalhadora na Inglaterra. São Paulo: Boitempo, 2010.

FILGUEIRAS, Vitor; CAVALCANTE, Sávio. What has changed: a new Farewell to the Working Class? Mimeo, 2018.

GASKARTH, Gyl. The Hartz Reforms...and their lessons for the UK. Centre for Policy Studies, 2014. Disponívelem: https://www.cps.org.uk/files/reports/original/141024133732-TheHartzReforms.pdf Acesso em: 28 jun 2019.

ILO. Ensuring decent working time for the future. International labour conference 10th session, 2018.

LANG, Carole; CLAUWAERT, Stefan; SCHÖMANN, Isabelle. Working time reforms in times of crisis. ETUI working paper, 2013. Disponível em: https://www.etui.org/Publications2/WorkingPapers/Working-time-reforms-in-times-of-crisis Acessoem: 28 jun. 2019.

MESSENGER, Jon. Working time and the future of work. ILO future of work research paper series, 2018.

OECD. The OECD Jobs Study: Facts, analysis, strategies, 1994. Disponívelem: https://www.oecd.org/els/emp/1941679.pdf acesso em 17jun 2019.

POLANYI, KARL. A grande transformação. Rio de Janeiro: Elsevier, 2012.

RIGOLETTO, Tomás \& PÁEZ, Carlos S. As experiências internacionais de flexibilização das leis trabalhistas. In: Organizadores: KREIN, José Dari; GIMENEZ, Denis Maracci; SANTOS, Luis Anselmo dos. Dimensões críticas da reforma trabalhista no Brasil (Org.) Campinas, SP: Curt Nimuendajú, 2018, p. 183-206.

SÁ, Teresa. "Precariedade"e "trabalho precário": consequências sociais da precarização laboral. Configurações. Revista de sociologia, n. 7, p. 91-105, 2010.

TEIXEIRA, Marilane Oliveira et al. Contribuição Crítica à Reforma Trabalhista. Campinas, SP: CESIT/IE/Unicamp, 2017.

UK-ONS (Office for National Statistic). Analysis of employee contracts that do not guarantee a minimum number of hours. United Kingdom, 2018a. 
VERGEER, Robert; KLEINKNECHT, Alfred. Do labour market reforms reduce labour productivity growth? A panel data analysis of 20 OECD countries (1960-2004). International Labour Review, v. 153, n. 3, p. 365-393, 2014 .

\section{Dados dos autores}

Vinícius Ferreira Lins

Doutorando em Economia na área de Desenvolvimento Econômico pela Universidade Federal da Bahia (UFBA), Mestre em Economia e Graduação em Ciências Econômicas na mesma universidade. Assessor do Sindicato dos Bancários da Bahia. E-mail: lins.vinicius@live.com

Adalberto Oliveira da Silva

Doutorando em Economia na área de Desenvolvimento Econômico pela Universidade Federal da Bahia (UFBA), Mestre em Economia Política pela Pontifícia Universidade Católica de São Paulo. E-mail: betoeco@gmail.com 